\title{
WestVirginiaUniversity
}

THE RESEARCH REPOSITORY @ WVU

Graduate Theses, Dissertations, and Problem Reports

2020

\section{Interpersonal Influences on Interpretation of Workplace Sexual Harassment}

\author{
Rachael E. Purtell \\ West Virginia University, rep0027@mix.wvu.edu
}

Follow this and additional works at: https://researchrepository.wvu.edu/etd

Part of the Communication Commons

\section{Recommended Citation}

Purtell, Rachael E., "Interpersonal Influences on Interpretation of Workplace Sexual Harassment" (2020). Graduate Theses, Dissertations, and Problem Reports. 7735.

https://researchrepository.wvu.edu/etd/7735

This Thesis is protected by copyright and/or related rights. It has been brought to you by the The Research Repository @ WVU with permission from the rights-holder(s). You are free to use this Thesis in any way that is permitted by the copyright and related rights legislation that applies to your use. For other uses you must obtain permission from the rights-holder(s) directly, unless additional rights are indicated by a Creative Commons license in the record and/ or on the work itself. This Thesis has been accepted for inclusion in WVU Graduate Theses, Dissertations, and Problem Reports collection by an authorized administrator of The Research Repository @ WVU. For more information, please contact researchrepository@mail.wvu.edu. 
Graduate Theses, Dissertations, and Problem Reports

2020

Interpersonal Influences on Interpretation of Workplace Sexual Harassment

Rachael E. Purtell

Follow this and additional works at: https://researchrepository.wvu.edu/etd

Part of the Communication Commons 


\title{
Interpersonal Influences on Interpretation of Workplace Sexual Harassment
}

\author{
Rachael E. Purtell
}

Thesis submitted

to the Eberly College of Arts and Sciences

at West Virginia University

in partial fulfillment of the requirements for the degree of

Master of Arts in

Communication Studies

\author{
Christine E. Rittenour, Ph.D., Chair \\ Elizabeth Cohen, Ph.D. \\ Scott A. Myers, Ph.D. \\ Department of Communication Studies
}

Morgantown, WV

2020

Keywords: workplace sexual harassment, Ambivalent Sexism Theory, interpersonal influence, marital dyads, close relationships, workplace culture, workplace social network

Copyright 2020 Rachael E. Purtell 


\begin{abstract}
Interpersonal Influences on Interpretation of Workplace Sexual Harassment Rachael E. Purtell
\end{abstract}

The purpose of this thesis is to investigate how women interpret and respond to incidents of sexual harassment at work, in the context of both their romantic relationships and workplace cultures. Incorporating Ambivalent Sexism Theory (Fiske \& Glick, 1995) to measure sexist attitudes, I presumed that their own, their partners' and their presumed workplace's sexism scores for both subsets would be linked to the women's perceptions and behavioral intentions in response to being sexually harassed at work. Participants were 145 heterosexual adult women, employed full-time and in self-defined committed heterosexual relationships. Each completed a survey that included the Ambivalent Sexism Inventory (ASI) (Fiske \& Glick, 1995), the Sexual Harassment Reporting Attitudes Scale (SHRAS) (Cesario, Parks-Stamm, \& Turgut, 2018), likelihood of reporting scenarios of sexual harassment $(\mathrm{SH})$, and number of special peers in the workplace. There was additional demographic data about the participants and their workplaces, most of which was incorporated as covariates. Results supported several of the asserted relationships. Although the predicted relationships between participants' and their perceived partners' and workplace sexist attitudes with reporting SH did not emerge, there were many significant findings regarding these variables and their associations with intolerance for SH. The majority of this study's findings emerged as significant, even when testing alongside covariates of education, organization size, organization type, and number of special peers in the workplace with the exception of perceived partner HS and intolerance for SH that were non-significant. Future research should explore disclosures exchanged regarding such incidents at work in the context of both romantic relationships and other social relationships in and out of work. 


\section{Thesis Defense}

Presented to Committee Members and Faculty of the Communication Studies Department at West Virginia University

July 14, 2020

Advisor

Christine E. Rittenour, Ph.D.

\section{Committee Members}

Elizabeth L. Cohen, Ph.D.

Scott A. Myers, Ph.D. 


\section{TABLE OF CONTENTS}

Chapter 1 - Literature Review........................................................ 1-20

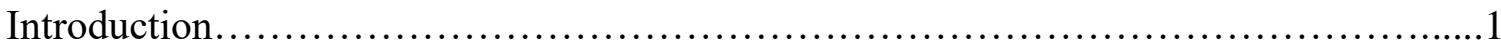

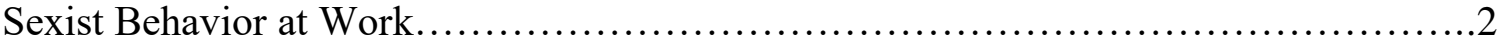

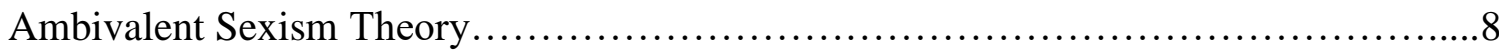

Benevolent Sexism.....................................................12

Hostile Sexism............................................................. 14

Marital Dyads and Organizational Behaviors.....................................15

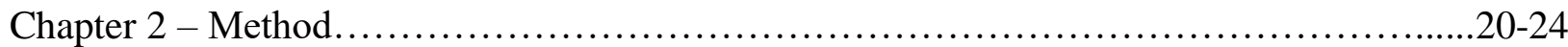

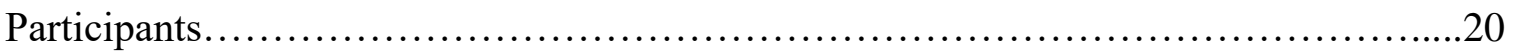

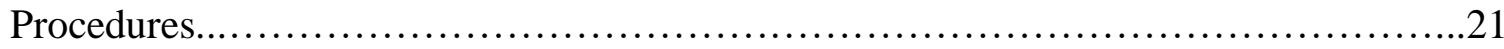

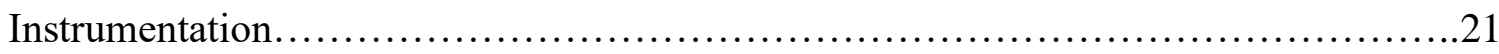

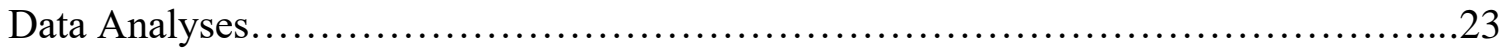

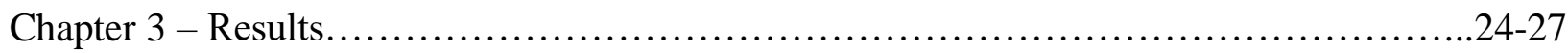

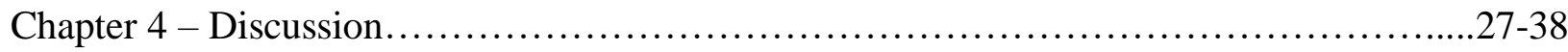

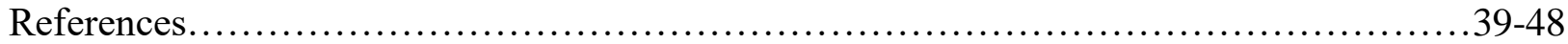

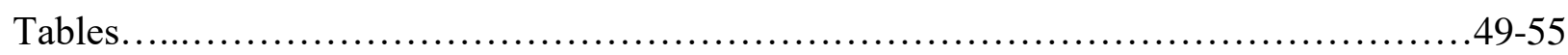

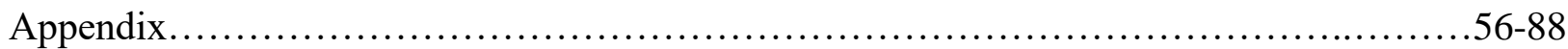




\section{CHAPTER ONE}

\section{Introduction}

In American culture, women are often subject to harassing sexual behaviors, most often perpetrated by men, communicating that women are expected to accept men's advances without question, thus decreasing their power in the interaction. This disproportionate perpetration of sexual harassment against women reflects an enduring power imbalance between men and women and there is no evidence to suggest that this trend has declined in recent years. Sexually harassing behaviors can range from groping or forced performance of a sexual act, to winking and flirting, all of which women are more likely than men to interpret as harassment (Rumrill, Stehel, Durana, \& Kolencik, 2018). Alongside the \#MeToo movement, women are gaining momentum in speaking out in opposition to such behavior, particularly in the workplace via the internet and social media (Karami, Swan, White, \& Ford, 2019). Many researchers have sought to determine the causes and ways to prevent sexist behavior in organizations (e.g., Keyton \& Rhodes, 1993; Keyton \& Rhodes, 1999; Keyton et al., 2001; Watkins, Kaplan, Brief, Shull, Dietz, Mansfield, \& Cohen, 2006; Keyton \& Menzie, 2007; Melgoza \& Cox, 2009; Mazerolle, Borland, \& Burton, 2012; Quesenberry \& Trauth, 2012; Settles \& O’Connor, 2014; Devine, Forscher, Cox, Kaatz, Sheridan, \& Carnes, 2017; Hughes, Schilt, Gorman, \& Bratter, 2017; Manuel, Howansky, Chaney, \& Sanchez, 2017; Acar \& Sümer, 2018; Finneman \& Jenkins, 2018; Conkel-Ziebell, Gushue, \& Turner, 2019; Goodwin, Graham, \& Diekmann, 2020; Lease, Shuman, \& Gage, 2020). Towards the goal to determine factors that influence women's intolerance and likelihood of reporting sexually harassing behaviors, my particular explanation stems from Fiske and Glick's (1995) Ambivalent Sexism Theory as it explains workplace sexual harassment as a consequence of men's ambivalent sexism - that which is derived from hostile 
and benevolent sexist attitudes. Hostile sexism - characterized by behaviors like groping and forced performance of a sexual act - is egregious and no longer seen as socially acceptable such that contemporary researchers have taken a greater interest in the nuances of benevolent sexism characterized by behaviors like winking and flirting - and how it functions to perpetuate gender inequalities as well as its associations with sexist behaviors in romantic relationships and the workplace (e.g., Viki, Abrams, \& Hutchison, 2003; Sümer, 2006; Moya, Glick, Expósito, de Lemus, \& Hart, 2007; Good \& Sanchez, 2009; Durán, Moya, \& Megías, 2011; Hammond, Overall, \& Cross, 2016; Hammond \& Overall, 2013; 2015; Hammond, Sibely, \& Overall, 2014; Ruiz, 2019).

Connecting communication across work and personal spheres, I also draw from previous research demonstrating that individuals' close interpersonal relationships may influence both sexist attitudes and workplace behaviors (e.g., Lenton \& Webber, 2006; Helms, Walls, Crouter,

\& McHale, 2010; Kapoor, Pfost, House, \& Pierson, 2010; Brands \& Kilduff, 2014; Kim \& Dew, 2016; Carnes, 2017; Huffman, Matthews, \& Irving, 2017; Umukoro \& Oboh, 2017; Xie, Shi, \& Ma, 2017; Yucel, 2017; Pepli, Godlewska-Werner, Po, \& Lewandowska-Walter, 2018). I assume that this effect will persist in terms of intolerance for and reporting of harassing behaviors at work. This review will explore different types of sexist behaviors at work, explicate Fiske and Glick's (1995) Ambivalent Sexism Theory, and address the known impacts of interpersonal relationships on organizational behavior.

\section{Sexist Behavior at Work}

Women across career fields and various leadership positions are subject to sexism within their organizations. This sexism can be communicated in words or via actions such as certain helping behaviors and circumvention of women in leadership positions. As Keyton and Rhodes 
(1993) pointed out, it can be difficult to distinguish sexual harassment from flirting behaviors at work, regardless of ethical ideology, so women in particular must be wary of any sexualized communication content at work. In fact, the same researchers pointed out, in a later study, that employees who perceived their work environment as sexually charged identified fewer verbal and nonverbal cues as sexual harassment, contrary to the hypothesized relationship. This suggests that sexual harassment is an organizational problem rather than a personal or interpersonal problem (Keyton \& Rhodes, 1999). Individuals who are victims of or working in organizations with highly sexually charged environments may inhibit those individuals' ability to recognize when workplace behavior is inappropriate because these sexualized behaviors are embedded in the organization's culture (Keyton \& Rhodes, 1999).

Keyton, Ferguson, and Rhodes (2001) developed and tested an organizational culture model to explain sexual harassment. This model posited that perceptions of social-sexual behavior at work were influenced by sex, target of the sexual harassment, and perceptions of fair interpersonal treatment of coworkers and supervisors. In turn perceptions of social-sexual behavior at work, as well as fair interpersonal treatment of supervisors, influenced the degree to which employees perceived organizations to adhere to their stated policies regarding sexual harassing behaviors at work. Their findings suggest that organizations may officially or unofficially sanction or encourage certain behaviors in their employees that may lead to increased sexual harassment (e.g., allowance of organizational romances).

Keyton and Menzie (2007) later identified some of the language structural properties and contextual factors that are present in sexually harassing communication. The language properties, or tangible traits in sexually harassing talk, were as follows: a personal relationship attempt by the sender, demonstration that the message was unwanted by the receiver, potential 
multiple meanings of the message, and sexualized content within the message. The contextual factors, or relative aspects of the setting in which the message occurred, were presumed or expressed power by the sender and contextualization of the work environment itself.

When sexist communication, attitudes, and behaviors occur at work, they are associated with a varietal plethora of physiological consequences for female employees and other negative outcomes related to perceived or actual organizational behaviors. Manuel, Howansky, Chaney, and Sanchez (2017) found that women who reported receiving great gender discrimination also reported greater job-related stress and symptoms of poor physical health as well as low autonomy and poor job security. They also found that a discriminatory work environment was associated with all employees coming in to work despite presence of physical illness out of fear of judgment or punishment (Manuel et al., 2017). This is problematic because sick employees tend to be less productive and their presence may also facilitate the spread of or prolonging their disease. Even before discrimination occurs at work, harmful effects stem from anticipatory socialization of these unfair acts. When evaluating children of both gender's career aspirations, anticipated gender discrimination negatively predicted career decision self-efficacy and vocational outcome expectations which in turn impact vocational goal-setting and career outcomes (Conkel-Ziebell, Gushue, \& Turner, 2019).

I employ Ambivalent Sexism Theory (Fiske \& Glick, 1995) alongside a few other explanations of these behaviors. Because women's experience of sexual harassment is linked to so many negative mental and physical health outcomes, many contemporary researchers have sought to explain why this behavior occurs and is often tolerated in the workplace. Sheppard and Aquino (2017) proposed their Sisters at Arms theory to explain female same-sex conflict and the problems it leads to for women in the workplace. Heilman and Caleo (2018) combined the Lack 
of Fit Model (M. E. Heilman, 1983) with gender bias processes in order to present strategies that may decrease lack of fit perceptions due to gender bias in the workplace and prevent negative expectations for discriminatory and employment outcomes. Most recently, Hideg and Shen (2019) proposed a theoretical model of the relationships between managers', partners', and women's benevolent sexism (BS) and women's attainment of leadership positions with mediating variables of managers' career and family support, partners' career support, and women's seeking career support from managers and partners and their perceptions of patronizing behaviors of supportive.

Watkins, Kaplan, Brief, Shull, Dietz, Mansfield, and Cohen (2006) conceptualized modern sexism as subtle and non-sexist in nature and found that it was positively related to the amount of men compared to women that employees seek advice from at work. Further, the researchers found an indirect relationship between modern sexism and the number of promotions employees received through the proportion of men whom employees seek advice from at work thus providing evidence that there is a relationship between sexism and career outcomes (Watkins et al., 2006).

Women in leadership positions are not immune to the consequences of sexism. For example, a study in Turkey revealed that male leaders were rated higher in perceived leader suitability compared to female leaders when the organization was performing well and female leaders were perceived as higher in leader suitability only when the organization was performing poorly, likely stemming from ideas about inherent differences in capabilities of men and women (Acar \& Sümer, 2018). Additionally, participants high in hostile sexism (HS) were more likely to associate female than male leaders with poor performance (Acar \& Sümer, 2018). On the bright side, one study revealed that college students' in Turkey's perceptions of successful middle 
managers are not overly masculine. Participants' perceptions prescribed both high relationshiporientation - a trait they perceived to be more associated with women in general compared to men - and high task-orientation - a trait they perceived to be more associated with men in general compared to women as desired qualities of a successful middle manager (Sümer, 2006).

Again, sexism impacts both sexes; beliefs can also impact communication skills necessary for highly paid male employees. Lease, Shuman, and Gage (2019) found that men's endorsement of traditional masculinity had a negative association with interpersonal competence related to conflict management and emotional support (Lease et al., 2020). The masculine and feminine scripts for workplace behavior have consequences for men and for women at work. Although men are perceived to be lacking stereotypically feminine qualities such as interpersonal competence, previous literature demonstrates that the consequences for women seem to be especially glaring for those employed in traditionally masculine professions because they are perceived to be lacking qualities necessary for success in such jobs. For example, female National Collegiate Association of Athletics (NCAA) athletic trainers reported encountering discrimination in their profession, particularly in the case of dealing with a male coach of a male sports team (Mazerolle, Borland, \& Burton, 2012). These athletic trainers also emphasized the importance of mentoring, establishing credibility through effective communication, and supervisor and staff support when facing instances of discrimination (Mazerolle et al., 2012). One study found that male police officers experience more positive emotions in the presence of other policemen compared to women in the police force implying that only men belong and can be successful in their career (Melgoza \& Cox, 2009). Settles and O’Connor (2014) investigated incivility and sexist climates perceptions at academic conferences and found that the relationship between these two constructs was stronger for women than it was for men. Furthermore, the 
results suggest that women in academia may be conditioned to expect sexism in their workplace since it did not significantly impact their reports of satisfaction with the conference they attended overall (Settles \& O’Connor, 2014). These results do imply, however, that the sexist climates of academic conferences reflect the unsuitable climate of their disciplines.

Devine, Forscher, Cox, Kaatz, Sheridan, and Carnes (2017) addressed the underrepresentation of women in the STEM field by designing an experiment to determine effective interventions to increase hiring of female applicants in STEM jobs. They found that interventions aimed at reducing gender biases were most effective suggesting that prejudice against women influences hiring decisions pre-intervention (Devine et al., 2017). This exemplifies the power of reducing bias in endeavors to reduce inequalities as a whole. Doctoral students in STEM, however, indicated their perception was that systematic discrimination was not a direct cause of the faculty gender gap, but they still had negative deterrent experiences with sexism due to a constructed innate gender difference and incompatibility with tenure track and the female body clock (Hughes, Schilt, Gorman, \& Bratter, 2017).

Athletics is another field where women face challenges posed by attitudes influenced by gender stereotypes. Finneman and Jenkins (2018) conducted a series of qualitative interviews to investigate the construction of perceived gender norms of sports entertainment consumers and how female sports reporters respond to viewers' discourse about these norms. They found that viewers often reinforce societal notions of gender via their public comments and that responses by reporters either challenged or reinforced viewers' asserted assumptions, however, most of the reporters in their sample refused to respond or react to these comments due to their sexist nature (Finneman \& Jenkins, 2018). This lack of addressing or combatting such problematic discourse on female reporters' appearances suggests that little progress has been made in terms of training 
reporters on how to respond to sexist discourse.

On the other hand, a study of women in the Information Technology (IT) workforce would suggest that self-perceptions of women as related to their career endeavors are changing. A series of qualitative interviews of women employed in IT challenged previous research suggesting that women represent a diversity of career anchors including technical competence and that these anchors are associated with varying levels of career satisfaction and turnover intention (Quesenberry \& Trauth, 2012). These findings suggest that women are becoming more comfortable and perceive themselves as competent in traditionally male-dominated fields despite the challenges they may face in hiring and in the workplace.

\section{Ambivalent Sexism Theory}

Born out of the desire to explain these sexist behaviors at work and inform training, prevention, and policies and procedures regarding these behaviors was Fiske and Glick's (1995) Ambivalent Sexism Theory. The theory focuses on the structural relationships between men and women, who are often in competition for both power and resources in the modern workplace. Harassing behaviors can be used to bar women from such power and resources in the workplace, especially if they are tolerated by the organization at large. As with all intergroup dynamics, the threat of the other group taking the more powerful group's resources (Turner \& Tajfel, 1986) prompt's the powerful group's members to think more negatively about and act more combatively toward the threatening outgroup's members. Still, the landscape of prejudice is more complex than these somewhat simple negatives. Fiske and Glick (1995) posit that sexual harassment is the consequence of complex interplay between motivations characterized by ambivalence (mixed feelings or contradictory ideas toward another) and stereotypes about femininity and women's place in the workforce (Fiske \& Glick, 1995). Men's motivational 
orientation toward women is characterized by ambivalence because of the competing nature of men's desire for both dominance and intimacy resulting in a mixture of positive and negative feelings toward women in general (Fiske \& Glick, 1995). This ambivalence combines inherently positive, benevolent motives and inherently negative, hostile motives which can be held by both men and women (Fiske \& Glick, 1995).

Both hostile and benevolent sexism are assessed based on three components: paternalism, gender differentiation, and heterosexuality (Fiske \& Glick, 1995). Paternalistic motivations stem from beliefs that men should treat women similarly to how a father would treat his children and characterizes women as weak and in need of protection (Fiske \& Glick, 1995). This behavior is described as paternalism because it is characterized by stereotyping women as less competent than, and in need of guidance from, men. Hostile paternalism is dominative in nature whereas benevolent paternalism is protective in nature (Fiske \& Glick, 1995). Gender differentiation is characterized by a need to make distinctions between men and women (Fiske \& Glick, 1995). Hostile gender differentiation is competitive in nature whereas benevolent gender differentiation is complementary in nature (Fiske \& Glick, 1995). Finally, heterosexuality emphasizes the unique relationships between men and women can be characterized by either hostility or a benevolent motivation for intimacy (Fiske \& Glick, 1995).

Fiske and Glick (1995) assert that different types of harassment are associated with particular motivations, reactions to rejection, and stereotypes. Earnest harassment is motivated by desire for sexual intimacy, where the reaction to rejection often depends on both the attractiveness of the woman and the likelihood the man will be successful in his advances, and is most often perpetrated against attractive women in stereotypical pink collar or female-dominated jobs. Hostile harassment is motivated by desire for domination, where the reaction to rejection is 
often an increase in hostility, and is most often perpetrated against nontraditional women in either stereotypical blue collar (lower in prestige) or white collar (male-dominated) jobs. Ambivalent paternalism is motivated by desire for sexual and/or relational intimacy or protectiveness over women, where the reaction to rejection is often a shift to hostility, and is most often perpetrated against traditional or attractive women in stereotypical pink collar jobs. Competitive harassment is motivated by desire for gender differentiation and/or sexual intimacy, where the reaction to rejection is often a shift to hostility, and is most often perpetrated against nontraditional or attractive women in either stereotypical blue collar or white collar jobs.

Women who are seen as attractive and nontraditional are the most likely to be harassed whereas traditional women may incur some protection from hostile harassment as a reward for their endorsement of traditional gender roles. Attractive women invoke desire for sexual intimacy in men whereas nontraditional women are seen as threatening to men, particularly in the workplace because the stereotypical male identity is characterized in part by work-oriented achievement in jobs that require characteristics that typically present men as being superior to women.

In a test of theory, high levels of hostile sexism (HS) among men were associated with higher levels of HS among women, gender differences in benevolent sexism (BS) had an inverse relationship with levels of overall sexism, and that the associations between HS and BS varied according to general levels of sexism across the country (Zakrisson, Anderzen, Lennell, \& Sandelin, 2012). Applied to the organizations, female respondents indicated that they perceived men to have an advantage in the workplace and women - having a disadvantage - thus hold more resentment (Feather \& Boeckmann, 2007).

Hostile sexism does not exist only in the workplace, but in our personal lives as well. 
Applied to mate selection, there were perceived positive associations between men's BS and female submissive characteristics in mate selection criteria, women's BS and male dominant characteristics in mate selection criteria, and HS and traditional imbalanced gender role norms in marriage for both genders (Chen, Fiske, \& Lee, 2009). These results imply that individuals of both genders are often drawn to partners who conform to gender stereotypes, thus perpetuating inequality within their own romantic relationships. The idea that benevolent ideologies perpetuate inequities in romantic relationships across cultures was further supported in a subsequent study examining both American and Chinese samples, replicating the same trends across both cultures (Lee, Fiske, Glick, \& Chen, 2010).

To reiterate, sexism is not only perpetrated by men or across sexes. Because of same-sex sexual harassment is commonplace and receives less awareness, DeSouza, Solberg, and Elder (2007) presumed it less likely to be interpreted as problematic by the general public. They employed Ambivalent Sexism Theory to investigate reactions to a hypothetical instance of samesex sexual harassment. Compared to man-to-woman sexual harassment, woman-to-woman sexual harassment was less likely to be seen as sexual harassment, worthy of investigation, and a punishable scenario. Women were more likely than men than to view woman-to-woman sexual harassment as sexually harassing, worthy of investigation, and punishable. Individuals associated with the LGBTQIA+ community, however, were more likely to see woman-to-woman sexual harassment as sexually harassing and worthy of investigation than individuals who were not associated with this community (DeSouza et al., 2007). Their collective findings confirm that women experience harassment at the hands of both sexes and their powerlessness is communicated in either scenario.

In sum, Ambivalent Sexism Theory (Fiske \& Glick, 1995) characterizes sexist attitudes 
toward women as being comprised of hostile sexist attitudes and benevolent sexist attitudes.

Hostile attitudes are characterized by punishing women who do not conform to gender stereotypes and benevolent attitudes are characterized by rewarding those who do conform. Communication reflecting hostile sexism is seen as overt, egregious, and generally not socially acceptable or tolerated within the workplace. Meanwhile, communication reflecting benevolent sexism is more subtle and positively valanced, thus they go unnoticed, unaddressed, and/or even rewarded in the workplace. Before articulating these concepts' employment in the current study, I further address previous research on both sexist behavior at work and interpersonal relationships that have employed benevolent and hostile sexism.

\section{Benevolent Sexism}

Benevolent sexism (BS) reflects attitudes that are positively valanced but still reinforcing of perceived gender differences. Therefore, BS is conceptualized as subjectively positive, but still discriminatory (Fiske \& Glick, 1995). Glick and Fiske (2011) described it as "the carrot aimed at enticing women to enact traditional roles" (p. 35). Although it presents as positive on the surface, it is still restrictive as it requires endorsement of gender roles and differences. Previous research has demonstrated that endorsing BS is associated with particular individual qualities, consequences for romantic relationships, and outcomes in the workplace. For example, there is a strong, positive association between women who endorse BS and their psychological entitlement, perhaps as a result of the societal benefits that BS offers women (Hammond, Sibley, \& Overall, 2014). Individuals high in BS are also more likely to endorse paternalistic chivalry, a belief system that restricts women's roles in intimate relationships (Viki, Abrams, \& Hutchison, 2003). In another study, both men and women indicated that they preferred romantic partners occupying traditional roles compared to those following an untraditional career path (Kapoor, 
Pfost, House, \& Pierson, 2010).

Hammond, Overall, and Cross (2016) asserted that women who are intimately involved with men whom they perceive to endorse BS reward, encourage and therefore foster sexist attitudes and therefore societal inequity for women at large. Furthermore, BS is associated with sexist attitudes regarding marital rights and duties related to intimacy such that exposure to a husband high in BS increases the perceptions of husbands' having the majority of marital rights, wives' duties, husbands' entitlement to those rights, wives' obligation to those duties, and that sex was a husband's marital right. It also decreased interpretations of a husband's sexual aggression perpetrated by a husband unto a wife as rape (Durán, Moya, \& Megias, 2011). Furthermore, this was mediated by participants' perceptions that sex was a husband's right and a wife's duty (Durán et al., 2011). Men who endorse BS, however, do exhibit increased investment in romance and family (Good \& Sanchez, 2009). In turn, women who endorse BS are more sensitive to difficulties and turbulence in their romantic relationships (Hammond \& Overall, 2013).

Sexist attitudes and behaviors in marriages and romantic relationships do not exist in a vacuum but carry over to other facets of life such as work. Both in romantic relationships and the workplace, benevolently sexist attitudes are associated with the kind of help or assistance an individual is willing to offer a woman and/or that a woman is willing to accept. For example, male partners who endorse BS provided their female partners with more dependency-oriented support and, in turn, their female partners felt less competent and less positively regarded compared to women whose male partners did not endorse BS (Hammond \& Overall, 2015). Additionally, women who endorsed BS provided more relationship-oriented support to their male partners who, in turn, perceived more positive regard and increased intimacy in their 
relationship compared to men with female partners who did not endorse BS (Hammond \& Overall, 2015). In the case of being advised not to engage in a dangerous or difficult task, benevolently sexist women were more likely to accept protectively justified outright prohibition imposed by their husbands, opposition without justification, or a group-based opposition (Moya, Glick, Expositto, de Lemus, \& Hart, 2007). Women who did not endorse BS only accepted a personalized justification for opposition to engaging in a dangerous task (Moya et al., 2007). These results suggest that it is difficult for women who do not endorse BS to differentiate between paternalistic discrimination and genuine concern by their male partners and colleagues and that women who do endorse BS seem to be willing to sacrifice some of their independence in exchange for male protectiveness.

In the workplace, women who received dependency-oriented help from male coworkers had lower perceived status compared to women who received autonomy-oriented help and the association of lower perceived status with receiving dependency-oriented help was actually strengthened for those low in BS (Ruiz, 2019). Similarly, women who receive dependencyoriented help were perceived as less competent compared to women who receive autonomyoriented help, again with the relationship strengthened for those low in BS (Ruiz, 2019). Although these helping behaviors may be altruistic in nature, providing assistance may not always be the best way for men to be allies for women, as dependency-oriented help reinforces gender stereotypes (Ruiz, 2019). Overall, previous literature demonstrates that although benevolent sexism is subjectively positive, it works to reinforce gender inequities in both the workplace and romantic relationships.

\section{Hostile Sexism}

Hostile sexism (HS) is conceptualized as subjectively negative and overtly discriminatory 
and harmful in nature (Fiske \& Glick, 1995). Glick \& Fiske (2011) described it as the "the stick to punish [women] when they resisted [enacting traditional gender roles]" (p. 35). HS, although no longer considered socially acceptable, is still present. Research demonstrates that women exposed to HS in the workplace will experience increased anxiety unless a female employee reported high system-justification therefore supporting of beliefs that men and women are inherently different (Pacilli, Spaccatini, Giovannelli, Centrone, \& Roccato, 2019). Another study found that HS contributes to the gender wage gap through its effect on supervisors' evaluations of their employees (Connor \& Fiske, 2019). HS is less interesting to contemporary researchers because it is not subtle and generally perceived as unacceptable and problematic across interpersonal and organizational contexts. Although there is little research on the effects of HS alone due to its outwardly discriminatory nature, the previous literature does still demonstrate its harmful psychological consequences for working women and how it continues to impact societal-level inequities across organizations.

\section{Marital Dyads and Organizational Behavior}

Marriages and romantic relationships are often studied in conjunction with organizational behaviors and outcomes. Marital and romantic partners often have significant influence over each other's attitudes due to the intimate nature of these relationships. Work-life balance is a popular topic in organizational communication research, but only a few studies have investigated this balance with sexism in mind. In a study of working class dual-career couples, it was found that, although nearly all dual-career couples experienced work-life balance problems, greater difficulties were reported by dual-career couples who worked in different organizations compared to those who worked in the same organization (Umukoro \& Oboh, 2017). Similarly, dual-earner couples' marital satisfaction was negatively predicted by reports of similar work- 
family centrality and was even lower for married couples who reported similar high levels of work-family centrality (Xie, Shi, \& Ma, 2017). Two-career couples also reported experiencing similar difficulties (Peplińska, Godlewska-Werner, Połomski, \& Lewandowska-Walter, 2018). Yucel's (2017) study provides even further evidence of the associations between work-life balance, stress, and wellbeing with physical and mental health acting as moderating variables.

In the case of romantic dyads with at least one member in the active military, both spouses perceived themselves as under-benefitting from their contributions to the family due to the psychological distress as result of crossover and spillover (Huffman, Matthews, \& Irving, 2017). Furthermore, such work-to-family conflict predicted less maintenance of household responsibilities by men (Huffman et al., 2017). Additionally, marriage can impact an individual's volunteerism such that a wife's soulmate view of marriage is negatively associated with one's own and one's partner's volunteering but positively associated with couple's volunteering (Kim \& Dew, 2016). On a lighter note, the results of yet another study suggested that the greatest marital satisfaction and equitable division of responsibilities related to the home occurred in coproviding spouses whose attitudes about breadwinning and employment were congruent with each other (Helms, Walls, Crouter, \& McHale, 2010). This leads me to believe that one's marital or romantic partner's sexist attitudes may influence their own attitudes and thus their interpretation and response to sexist behavior at work.

\section{Rationale/Hypotheses}

Sexism and sexual harassment is a pervasive topic in American society. In the wake of comments endorsing harassing behavior made by President Donald Trump in his 2016 campaign, many women began speaking publicly about their experiences with sexual harassment and assault (see Jenkins and Mazer's (2018) analysis of over 1,000 tweets on Twitter). This analysis 
uncovered four major themes: common characteristics of sexual assault, relationships to the perpetrator of the assault, whether the incident occurred in a public or private location, and most relevant to the proposed thesis - the actions taken to address the assault and the consequences of those actions. In general, women are more likely to report incidents of sexual harassment or assault than are men and reporting has also been positively linked to characteristics like trait moral courage and fairness moral concerns and negatively linked to loyalty and Narcissism (Goodwin, Graham, \& Diekmann, 2020). Although many victims of sexual harassment are reluctant to report the incidents, Walker, Buggs, Taylor, and Frazier (2019) assert that reporting is essential in order to effectively analyze data on sexual harassment so that organizations may design policies and training procedures for their employees.

Many scholars have investigated links between sexist behavior in the workplace and particular individual and organizational constructs. Much of the literature has also addressed the challenges of balancing work life and family life but influence of home life on workplace behaviors has commanded little attention. Very little research has addressed the especially consequential impact of the influence of individuals' close personal relationships on their behavior at work in relation to intolerance and reporting of such behavior in organizational settings. In addition, research also suggests that certain skills known for being advantageous in the workplace may also benefit individuals in their home and marital life. For example, one study found that political skill can be used as a coping mechanism to lessen the impact of spillover of work stress to the home and can help men see their own role overload related to work-life balance as less distressful to their wives (Carnes, 2017). Because Ambivalent Sexism Theory (Fiske \& Glick, 1995) was born out of interest in investigating sexual harassment in the workplace, the proposed thesis employs this theory to determine how women's close 
interpersonal relationships affect both their intolerance and reporting of sexual harassment in their workplace.

Given the challenges of balancing work with marriage demonstrated by previous research (e.g., Helms et al., 2010; Kim \& Dew, 2016; Carnes, 2017; Huffman et al., 2017; Peplinska et al., 2017; Umukoro \& Oboh, 2017; Yucel, 2017; Xie et al., 2017) it is logical that individuals in marital dyads have some influence over each other's' behavior in the workplace. Further, Hammond and colleagues (2016) demonstrated that women's endorsement of benevolent sexism is in fact dependent on their perceptions of their own close relationships. As men and women's endorsement of hostile sexism is associated with competition with other women and both men and women's endorsement of benevolent sexism is associated with maintaining gender inequality (Hammond \& Overall, 2017) the first two hypotheses are posited:

H1: Women who perceive their committed male partners as high in benevolent sexism (BS) will show a (a) negative association with reporting of sexual harassment $(\mathrm{SH})$ and (b) negative association with intolerance of $\mathrm{SH}$.

H2: Women who perceive their committed male partners as high in hostile sexism (HS) will show a (a) negative association with reporting of sexual harassment $(\mathrm{SH})$ and (b) negative association with intolerance of SH.

Fiske and Glick's (1995) Ambivalent Sexism Theory asserts that both BS and HS are associated with sexual harassment in the workplace. Jacobson and Eaton (2018) also conducted two studies with both undergraduate college students and Human Resources professionals in which participants were exposed to a fake company's website which either outlined a zerotolerance policy for sexual harassment, a standard policy, or no policy. Participants were then exposed to a scenario depicting either a moderate or severe instance of sexual harassment and 
results indicated that participants in the zero-tolerance policy condition were the most likely to report the incident, especially for the moderate incidents. Furthermore, Walker and colleagues (2019) posited that a climate of psychological safety in which individuals feel safe disclosing incidents of SH is essential for reduction and prevention of these behaviors in the workplace. Despite Ambivalent Sexism Theory's inception over 20 years ago, research as recently as last year still calls for greater attention to and investigation of both HS and BS occurring in organizations (i.e., Chawla, Wong, \& Gabriel, 2019). Thus, I posit the current study's third and fourth hypotheses:

H3: Female employees in organizations they perceive as high in BS will show a (a) negative association with reporting of sexual harassment $(\mathrm{SH})$ and $(\mathrm{b})$ negative association with intolerance of $\mathrm{SH}$.

H4: Female employees in organizations they perceive as high in HS will show a (a) negative association with reporting of sexual harassment $(\mathrm{SH})$ and $(\mathrm{b})$ negative association with intolerance of $\mathrm{SH}$.

Because men's endorsement of both BS and HS are associated with the perpetration of SH (Fiske \& Glick, 1995), and given aforementioned parallels between work-life and personallife ideological constructs, it is logical to assume that women's endorsement of both BS and HS will be associated with reporting and tolerance of $\mathrm{SH}$ in the workplace. Thus, the final two hypotheses are posited:

H5: Female employees high in BS will show a a (a) negative association with reporting of sexual harassment ( $\mathrm{SH}$ ) and (b) negative association with intolerance of SH.. H6: Female employees high in HS will show a a (a) negative association with reporting of sexual harassment ( $\mathrm{SH}$ ) and (b) negative association with intolerance of $\mathrm{SH}$. 
In Kassing's (2000a, 2000b) investigations of employee dissent, a reported limitation of both studies was that information on organization type and workplace conditions were not collected. Kassing suggested that future research on employee dissent should examine these characteristics. Because expressions of dissent can be likened to reporting of sexual harassment at work, the following were collected as covariates: participants' organization size, whether or not the participants telecommute, work experience in years, current employment in years, position, and organization type. Expressions of dissent, solidarity, and trust are influenced by the quality of peer coworker relationships (see Sollitto \& Myers, 2015; Myers \& Johnson, 2004), regardless of organization type (see Spillan \& Mino, 2001), and so participants were also asked how many special peers, or coworkers with whom they share a great deal of intimacy and selfdisclosure with, they have at work (Kram \& Isabella, 1985). In line with these, the current study investigates the following research question:

RQ: When controlling for relational, socioeconomic, and characteristics of one's position and career field, do the associations remain among the participants' perceived partner BS and HS, workplace BS and HS, their own BS and HS, and their likelihood to report and intolerance for $\mathrm{SH}$ ?

\section{CHAPTER TWO}

\section{Method}

\section{Participants}

A total of 375 people logged in to Qualtrics to offer their voluntary participation in a study that was introduced with the following criteria: women with a minimum age of 18, who are either married or in a self-categorizing committed romantic heterosexual relationship lasting three years or more and are employed full-time at a workplace in which they frequently interact 
with both men and women. After removing the individuals that omitted answers to over half of the survey $(n=192)$ and the individuals who reported that they were single, never married, widowed, separated, or divorced and those who indicated that they did not view any presented scenarios as sexual harassment $(n=5)$ (see Instrumentation for further information on removal of these participants) $(n=38)$, participants were 145 heterosexual adult women. The participants' ages ranged from 18 to 62 years $(M=32.28, S D=13.11)$. The sample was primarily $83.4 \%$ White/Caucasian $(n=121)$, and also was $2.8 \%$ Hispanic or Latino $(n=4), 5.5 \%$ Black/African American $(n=8), 4.8 \%$ Middle Eastern $(n=7)$, and 2.1\% Asian or Pacific Islander $(n=3)$. See Table 1 for additional demographic information about the sample.

\section{Procedures}

After IRB approval, participants completed an anonymous online survey administered via Qualtrics. Participants were recruited via snowball sampling through undergraduates enrolled in introductory communication courses at a large university in the Midwest United States and via Facebook. Students received an email from their instructors with the cover letter attached (see Appendix) and the survey link and were asked to recruit participants who fit the inclusion criteria and to provide them with the link. Students received marginal extra credit for referring a participant. In addition to the aforementioned demographics, the forthcoming scales included to assess all hypothesized variables and covariates.

\section{Instrumentation}

Benevolent and Hostile Sexism. The ASI (Fiske \& Glick, 1995) is a 22-item measure that asks participants to rate on a 7-point Likert-type scale, ranging from Strongly Disagree (1) to Strongly Agree (7) their agreement with statements about the roles of men and women, and relationships between them. They completed the 22-items for each of these: participants' own 
perceptions, perceptions of their romantic partner's perceptions, and their organization's benevolent sexism (BS) and hostile sexism (HS), but the scale was reduced to 19 items in all data analyses (see "data analysis" section below). These three sets were randomized in order to control for order effects. In this study, a reliability coefficient alpha of .79 was obtained for perceived partner BS $(M=4.10, S D=0.93), .88$ for perceived partner $\mathrm{HS}(M=3.80, S D=1.05)$, .83 for perceived workplace BS $(M=3.89, S D=1.05), .87$ for perceived workplace HS $(M=$ 3.68, $S D=1.05), .84$ for participant BS $(M=3.72, S D=1.09)$, and .88 for participant $\mathrm{HS}(M=$ $3.52, S D=1.11)$

Intolerance for Sexual Harassment. The SHRAS (Cesario et al., 2018) is a general assessment of an individual's attitudes toward reporting an incident of sexual harassment at work. It is an 18-item measure that asks participants to rate their agreement on a 7-point Likerttype scale, ranging from Strongly Disagree (1) to Strongly Agree (7). In this study, a reliability coefficient alpha of .90 was obtained $(M=5.40, S D=0.90)$. While low scores indicate lower intolerance for $\mathrm{SH}$ and higher scores indicate high intolerance for $\mathrm{SH}$.

Likelihood of Reporting Sexual Harassment. To supplement the previous scale's assessment of sexual harassment tolerance, I assessed specific behaviors that participants may (or may not) deem "sexual harassment" and assessed likelihood of reporting to a supervisor. For the first of these, sexual harassment deeming, each of the 4 behaviors were assessed separately for both self and other as target. These 8 items were adapted from Cohen, Myrick, and Hoffner (2019), with the newly included "is this sexual harassment?" items recommended by the prospectus committee. Specifically, those behaviors were an unwanted sexual comment, inappropriate touching, inappropriate exposure of genitals or breasts, and an unwanted solicitation for sex since this measure was created in light of allegations of major harassment 
scandals in Hollywood. These behaviors display a range of the severity of harassment but can still be recognized as communicating sexual harassment. Responses options were "yes" and "no" for each item. Participants' responses to these 8 items asking whether or not they would report the behavior if it happened to them or a coworker were combined to create a ratio variable indicating how many of these scenarios participants would report to a supervisor with responses ranging from 0 ("yes, this is harassment" for none of the items) to 8 ("yes, this is harassment" for all items $)(M=6.02, S D=2.19)$. All participants who reported "no" for all of the 8 items were removed from all hypothesis testing, because if they did not view these behaviors as such they were not going to report them and thus were not useful for use in meeting the goals of this research.

For the second of these, realistic nature of the items, I included an additional assessment that is not employed in hypothesis testing, to check for validity and tease out those who did not interpret harassing behavior as harassing of "Please indicate how realistic it is for each of these behaviors to occur in the workplace" on scale of 1-7 with 1 being Extremely Realistic and 7 being Extremely Unrealistic. This was asked 8 times in reference to each of the aforementioned behaviors (unwanted sexual comment, inappropriate touching, inappropriate exposure of genitals or breasts, and an unwanted solicitation for sex) and - while not included in the hypothesis testing - resulted in moderately realistic range of responses, as inferred from the composite score of all 8 items $(M=3.66, S D=1.57)$. See Table 3 for the items and responses to this measure.

Income, education, and romantic relationship satisfaction. In addition to the demographic variables listed above, participants' income, education, and relationship satisfaction were also collected for use as covariates. 
Kassing's categories of organization type and conditions. Data was also collected regarding participants' organization size, whether the participants telecommute, work experience in years, current employment in years, position, and organization type for use as covariates.

Special peers. In this survey, special peers were defined as peers in the workplace with whom the participant has a great degree of self-disclosure and self-expression (Kram \& Isabella, $1985)$, with participants identifying the number that they have $(M=5.24, S D=7.96)$.

\section{Data Analyses}

After cleaning the data (removing the individuals who either did not complete the survey or did not fit the inclusion criteria based on their relationship status) and I tested the data for abnormalities. Doing so showed no concerns with skewness, nor kurtosis, and that the majority of the scales were reliable. One scale - the ASI - yielded poor reliabilities of each of the benevolent sexism subscales, which stemmed from items of "In disaster, women ought not necessarily to be rescued before men," "People are often truly happy in life without being romantically involved with a member of the other sex," and "Men are complete without women." The unreliable responses to these reverse-coded items may be attributable to the items' negative phrasing (which is problematic in that it is confusing for the participants) and their focus on the heterosexual intimacy and protective paternalism portions of benevolent sexism. I removed these items from my hypothesis and research question assessments. I ran Pearson product moment correlations to test my hypotheses. To test the RQ, I ran partial correlations in which I controlled for the covariates while (re)assessing the hypothesized correlations among the variables of sexual harassment tolerance sexism. All statistical tests were performed via SPSS.

\section{CHAPTER THREE}

\section{Results}


Hypothesis 1 predicted perceived partner's benevolent sexism's (BS) (a) negative relationship with perceived and reporting $\mathrm{SH}$ and (b) its negative association with intolerance for SH. Results of a Pearson correlation revealed a significant negative relationship between perceived partner's BS and reporting of SH $r(143)=-.184, p=.027$. Results of Pearson correlation were insignificant and did not support hypothesis $1 \mathrm{~b}, r(143)=-.119, p=.156$, thus the hypothesis was partially supported.

Hypothesis 2 predicted perceived partner's hostile sexism's (HS) (a) negative relationship with perceived and reporting SH and (b) its negative association with intolerance for SH. Results of a Pearson correlation were insignificant and thus did not support hypothesis $2 \mathrm{a}, r(143)=-$ $.129, p=.123$. However, hypothesis $2 \mathrm{~b}$ 's predicted negative relationship between perceived partner's HS and intolerance for SH was supported. Results of a Pearson correlation revealed a significant, negative relationship, $r(143)=-.183, p=.027$ such that as perceived partner's HS increased, favorable attitudes toward reporting workplace $\mathrm{SH}$ in general decreased. Thus, $\mathrm{H} 2$ is partially supported.

Hypothesis 3 predicted workplace BS's (a) negative relationship with perceived and reporting $\mathrm{SH}$ and (b) its negative association with intolerance for SH. Results of a Pearson correlation were insignificant and thus did not support hypothesis $3 \mathrm{a}, r(143)=-.036, p=.665$. However, hypothesis 3b's predicted negative relationship between workplace BS and intolerance for SH was supported in that results of a Pearson correlation revealed a significant, negative relationship, $r(143)=-.237, p=.004$. As perceived workplace BS increased, favorable attitudes toward reporting workplace SH decreased. Overall, hypothesis 3 was partially supported.

Hypothesis 4 predicted workplace HS's (a) negative relationship with perceived and reporting SH and (b) its negative association with intolerance for SH. Results of Pearson 
correlations revealed a significant negative relationship between perceived workplace HS and reporting of SH $r(143)=-.172, p=.038$. Hypothesis 4b's predicted negative relationship between workplace $\mathrm{BS}$ and intolerance for $\mathrm{SH}$, was also supported. Results of a Pearson correlation showed a significant, negative relationship between the variables, $r(143)=-.281, p=$ .001 such that as perceived workplace HS increased, favorable attitudes toward reporting workplace SH decreased. Thus, hypothesis 4 was supported.

Hypothesis 5 predicted participants' BS's (a) negative relationship with perceived and reporting $\mathrm{SH}$ and (b) its negative association with intolerance for $\mathrm{SH}$. Results of a Pearson correlation were insignificant and thus did not support hypothesis $5 \mathrm{a}, r(143)=-.098, p=.241$. However, hypothesis 5b's predicted negative relationship between participants' BS and intolerance for SH was supported. Results of a Pearson correlation revealed a significant, negative relationship was revealed, $r(143)=-.204, p=.014$ such that as participant BS increased, favorable attitudes toward reporting workplace $\mathrm{SH}$ in general decreased. Overall, hypothesis 5 was partially supported.

Hypothesis 6 predicted participants' HS's (a) negative relationship with perceived and reporting $\mathrm{SH}$ and (b) its negative association with intolerance for SH. Results of a Pearson correlation were insignificant and thus did not support hypothesis $6 a, r(143)=-.114, p=.171$. However, hypothesis 6b's predicted a negative relationship between participant HS and intolerance for SH was supported. Results of a Pearson correlation revealed a significant and negative relationship was revealed, $r(143)=-.339, p<.001$ such that as participant HS increased, favorable attitudes toward reporting workplace SH in general decreased. Overall, hypothesis 6 was partially supported. 
Because perceived partner's HS, perceived workplace BS and HS as well as participant BS and HS each had significant, albeit small, correlations with tolerance for $\mathrm{SH}$, partial correlations were run to control for income, education, organization size, organization type, and number of special peers in the workplace. After doing so, all the hypothesized relationships remained significant with only slight decreases, with the exceptions of the hypothesized relationship between participant $\mathrm{HS}$ and tolerance for $\mathrm{SH}$ which remained significant but increased slightly and the hypothesized relationships between partner HS and tolerance for SH and between workplace HS and reporting SH which became insignificant. See Table 3 for these partial correlations and Table 4 for the full correlation matrix between demographic variables and hypothesized variables.

\section{CHAPTER FOUR}

\section{Discussion}

In a study about sexist communication at work, findings demonstrate that both women's relationships and work environment may influence how they interpret and respond to such behavior. Hypothesized relationships emerged between participants' intolerance for sexual harassment (SH) at work and the following variables: perceived partner's hostile sexism (HS) workplace benevolent sexism (BS), workplace HS, participants' BS, and participants' HS. All of these associations, with the exceptions of perceived partner HS and intolerance for SH and between workplace $\mathrm{HS}$ and reporting $\mathrm{SH}$, remained significant even when accounting for covariates such as education and number of special peers in the workplace. No hypothesized relationships emerged surrounding participants' likelihood of reporting hypothetical scenarios of SH. In this discussion, I review this study's support and extension of previous research on sexist 
communication at work, its practical implications for women in the workplace, and the study's limitations and future directions.

\section{Gender Stereotypes and Social Networks}

This study suggests the strong interplay between workplace culture, social networks at work, and sexist attitudes in romantic dyads in perpetuating sexist communication at work. As workplace communication does not exist in a vacuum, sexist attitudes carry across professional and personal contexts. In addition to its aforementioned correlates that represent likely consequences (i.e., sexism scores and attitude toward reporting sexual harassment), sexist attitudes likely impact an individual's choice in friendships. This is suggested by previous research. Men who reported greater BS also had fewer cross-sex friendships (Lenton \& Webber, 2006). Although sexism was not a predictor of female participants' cross-sex friendships, women who were more masculine reported having more cross-sex friendships, as compared to more feminine women (Lenton \& Webber, 2006). Another study demonstrated that, women were more likely to seek out men in traditionally male-dominated careers for friendship, compared to women in general or men in other fields (Kapoor et al., 2010). This body of literature suggests that gender stereotypes are salient when interacting with and befriending members of the opposite sex, it is likely these biases influence how we build our social networks both in and out of work.

\section{Underlying Motivators in Workplace Friendships}

Friendships at work may influence women's perceptions of right and wrong in dealing with incidents of SH. Although not much has been done to establish links between workplace friendships and sexist behavior at work, it does appear that sexist attitudes may impact the choices individuals make regarding whom they include in their close interpersonal circle, and 
those that they depend on for loyalty and helping concerns. For example, moral concerns with loyalty are negatively predictive of reporting of sexual harassment (Goodwin, Graham, \& Dieckmann, 2020). Additionally, Zhu, Restubog, Leavitt, Zhou, and Wang (2020) found that moral identity symbolization in the workplace is associated with helping behaviors such as reporting an incident of $\mathrm{SH}$ as a bystander, but this effect only persists if there is an ongoing relationship between those who perform such a moral identity and those witnessing instances of SH. Taken together, the results of this study suggest that our relationships with both victims and perpetrators of SH complicate how we interpret and respond to issues of sexually harassing behavior at work. To further tease out the interplay of loyalty, helpfulness, and other likely considerations such as perceived fairness, morality, social support, and relationship vs. task orientation, much more investigation concerning the relationship between workplace friendship networks and tolerance and reporting of sexual relationships is necessary.

\section{Workplace Culture and Sexual Harassment}

Moving beyond the individual motivations to the broader workplace culture, another major takeaway from the results of this study is that workplace culture perceptions are so pervasive that they correlate (and may likely influence, as could be studied with more complex procedures) with women's attitudes about reporting sexual harassment in general. This is suggested by the correlations between workplace HS and BS and attitudes about $\mathrm{SH}-$ an association that emerged regardless of participants' ability to identify sexually harassing behaviors at work. In addition to supporting previous applications of Ambivalent Sexism Theory (Fiske \& Glick, 1995), as discussed in the literature review, this study supports previous literature asserting that workplace $\mathrm{SH}$ is a cultural problem rather than an individual problem (Keyton, et al., 2001). Keyton and colleagues (2001) even suggested that organizations may 
unintentionally sanction some behaviors that may encourage SH in their workplace policies. For example, allowance of workplace romance may encourage an organization's members to engage in "flirting" behavior with each other, which can become problematic and constitute SH when there is a power imbalance between the two individuals in the workplace. Also, having a dress code that does not require women in the workplace to dress conservatively - although perhaps intended to grant female employees freedom of expression in the workplace - may be interpreted by male coworkers as acceptability of sexually harassing behaviors such as cat-calling or unwanted sexual comments or solicitations. These arguments are not to suggest that men are not sexually harassed at work, but they are more commonly the perpetrators in the workplace. Additionally, in a survey of American adults, $43 \%$ of women reported that they had been a victim of sexual harassment compared to only $12 \%$ of men (Rumrill, Stehel, Durana, \& Kolenick, 2018) emphasizing the pervasiveness of workplace cultures that disproportionately disenfranchise women from protections against $\mathrm{SH}$.

A related takeaway is that participants' HS and BS are linked and often co-communicated but have distinctive contributions to perpetuating a workplace culture of sexism. Unlike other forms of discrimination, sexism is unique because it relies on the celebration of differences between men and women rather than derogation of group differences, thereby complicating the ingroup-outgroup relationship. Previous literature even suggests that women who are sexist earn themselves protection from harassment because they do not reject (and may even reinforce) notions of gendered stereotypes (BS) and thus do not bring out some of the more egregious behaviors in their male coworkers that would be characterized as HS (Fiske \& Glick, 1995). Women who have higher degrees of HS are less likely to report sexually harassing behaviors and 
have more negative attitudes toward reporting sexual harassment in general thus unintentionally sanctioning sexually harassing behavior perpetrated by male coworkers.

\section{Sexism and Major Life Choices}

Despite the emergence of a link between partners' HS and participants' own tolerance for $\mathrm{SH}$ as predicted by the sixth hypothesis, the findings for the research question suggest that women and men make major life choices and develop attitudes similarly across adjacent facets of life (i.e., relationships and work). The relationship was initially supported with bivariate correlations but became insignificant when covariates were entered, suggesting that education influences both attitudes and decisions surrounding both workplace and more intimate relationships as well as our behavior at work. In fact, previous research demonstrates a negative relationship between education attainment and both hostile and benevolent sexism (Glick, Lameiras, \& Castro, 2002). Education likely influences our choices of close others, those people who may reinforce or influence opinions of what constitutes as sexual harassment or as acceptable behavior in the workplace. For example, nearly $70 \%$ of the current sample completed some college and may be more likely to identify benevolent behaviors for instance as sexist. However, it is impossible to know from this data for sure if education is truly causal when it comes to choices of sexist partners and tolerance for $\mathrm{SH}$, but it leaves room for further investigation and future inquiries.

\section{Perceived Partner Benevolent Sexism and Reporting of Sexual Harassment}

Although the hypothesized negative relationships between perceived partner BS, workplace HS and reporting SH emerged as significant, the associations were small. This suggests that influences of perceived partner BS and workplace HS on reporting SH are slight. Regarding perceived partner BS and reporting SH, male partners may even support the action of 
reporting an incident of $\mathrm{SH}$ in a way that communicates other benevolently sexist ideals. For example, such a relationship may be explained by a husband or boyfriend's desire to play a role in which he is the hero to his female partner who is experiencing SH at work. Such support may communicate values of benevolence and protective paternalism as well as provide dependencyoriented help which is limiting to women as it reinforces gendered stereotypes that suggest women are weak and need protection and assistance (Ruiz, 2019). As much as both types of sexism are harmful, considering this finding of this study reminds researchers that no construct is completely, nor inherently positive or negative. BS is complicated because it is seemingly positive but carries undertones that limit women to socially enforced gender roles. Conversely, the small negative association between workplace HS and reporting SH may be explained by the fact that egregious behaviors such as groping - which are characterized by HS - are no longer seen as socially acceptable so individuals may report them at their workplace regardless of whether or not these behaviors are perpetuated by the organizational culture.

\section{Limitations and Future Directions}

This study's biggest limitation was that many individuals who logged on to complete the survey did not fit the inclusion criteria outlined in the advertisement and cover letter for the study. Requested participants were full-time employed women who are married or in a committed monogamous heterosexual relationship, however, many individuals indicated that they were either single, separated, divorced, or widowed. This effectively eliminated nearly a fourth of what would have been viable data for analyses. However, it was interesting to observe that there were many individuals who did not "fit" the relationship status demographics we were looking for but still chose to complete the survey. Several things may be at play underneath this seeming divergence from the criteria. First, women who are separated, divorced, or widowed 
may still consider that partner as extremely influential regarding their attitudes and behaviors surrounding sexual harassment at work. Second, perhaps those same labels somewhat confined the participants such that they were not accurately able to select and reference the presence of a newer relationship after a separation, divorce, or death of a partner. Third, those who indicated that they were single may feel that their input was still valuable because of influences from previous relationships. Future studies should broaden the inclusion criteria and collect more those in various relationship types. It is possible that students did not read the instructions in the recruitment email in full and logged on and completed the survey themselves rather than finding a participant who fit the desired inclusion criteria. If future researchers wish to recruit participants who fit these demographics via snowball sampling through students, they may wish to provide students with the instructions, but withhold the survey link and ask them to send the contact information of the participants they recruit and then provide those participants with the survey link. Future researchers may also wish to recruit participants in organizational settings through organizations and/or systems like MTurk that allow researchers better access to the working community. Furthermore, it may be useful to include a device in Qualtrics which denies participants access to the survey if they do not fit the desired demographics.

Another limitation of this study concerns the reliability of the employed Ambivalent Sexism Inventory (ASI) (Fiske \& Glick, 1995) for perceived partner ASI. When analyzing the data, we found that the three reverse-coded items on the BS subscale of the ASI significantly decreased the overall reliability of the scale. Their low reliabilities may be based on outdated ideals of gender roles reflective of the time the scale was created and were also worded with double negatives such that it may have become difficult for participants to rate these items for another individual. These problems suggest that rigorous measures be taken to improve the 
measurement of this construct. Furthermore, components and displays of sexism and gender roles have evolved in the 25 years since this scale was created and thus it may be necessary to reevaluate the instrument's current effectiveness.

In addition to the items themselves, the study is limited by its inclusion of only the participants' perceptions of the other players at work and at home. Although measuring participants' perceptions of their partners' sexism may not accurately capture their partners' true sexism, the choice to measure perception is useful because how an individual thinks their partner feels and behaves may be (more) indicative of how the participants' act and respond in relation to these presumed beliefs. Previous research suggests that spillover of work-related stress over time is negatively associated with marital satisfaction, interactions, and attributions (Brock \& Lawrence, 2008) thus it is possible that marital/relationship stress may spillover into the workplace context as well. Future research may seek to collect dyadic data from married couples or see how sexist communication in marital dyads spills over to non-work facets of life.

Another major limitation in this study was the lack of an established, reliable behavioral measure for reporting SH. While the previously employed scale by Cohen and colleagues (2019) pinpoints a range of behaviors to be considered as sexual harassment in the organizational context, the true experience of inappropriate behaviors is very idiosyncratic, thus creating great possibility that participants have trouble quickly and accurately deciding on a definitive response. Few of the associations between this measure and any of the other variables emerged as significant and it was interesting that there were a small number of participants who did not view any of these behaviors as sexually harassing, albeit their egregious nature. Perhaps it was because this measure failed to capture the realities of day-to-day sexual harassment since it was created in light of allegations of major harassment scandals in Hollywood. Sexual harassment 
may manifest differently in the types of organizations that this study's participants were a part of such that they reported that these scenarios were only somewhat realistic to occur in their own workplace. Additionally, it may be useful to use a Likert scale in place of or in addition to the measure tallying the number of scenarios participants would report in order to assess the degree to which each behavior is harassment for extra utility. Other measures also seem to fall short. Goodwin, Graham, and Diekmann (2020) employed a similar measure in their investigation of sexist behavior at work, but only asked participants whether they would report a single scenario involving an unwanted sexual comment during an online collaborative exercise. This measure was considered for the study but was ultimately rejected because it did not cover the hierarchy of potentially sexually harassing behaviors. Future researchers should seek to develop a more reliable and consistent behavioral measure for reporting SH at work, though actual report are - of course - the very best data to obtain. Furthermore, perhaps researchers may study complex behaviors motivated by sexism by employing more observational and qualitative methods such that we may reevaluate how we measure responses to such behaviors through a more in-depth understanding of how they are experienced in the workplace. With more informative data on these experiences, perhaps future scholars can develop measures that are more reflective of the behaviors and interactions characterized by sexism that actually occur.

To address the final limitation of the heteronormative sample, future research may also consider other types of relationship outside of monogamous, heterosexual marriages and longterm relationships. Future studies should explore dynamics of both single working women and women in committed non-heterosexual relationships, as both invite the opportunity to explore bonds between women. Same-sex female romantic relationships, by their very structure, challenge the norms posited by this study's employed theory, and commonly emphasize equality 
(Horne \& Biss, 2009) suggesting that future explorations would require method and theory unique to those in this study. However, individuals in these nontraditional relationships still live within this sexist system and thus are subjected to its consequences, and so future researchers might even explore how these individuals and their monogamous, heterosexual allies challenge this system in their workplace and more intimate communication spheres concerning gender roles, power, and justice in the workplace. These studies should further investigate the role of special peers because they are likely to be allies given the previously discussed nature of selfdisclosure. Special peers in the workplace are important when dealing with sexist behavior at work because of their high degree of self-disclosure. Previous research indicates that behaviors like expression of dissent and solidarity are indicative of the quality of relationships among coworkers (Sollitto \& Myers, 2015; Myers \& Johnson, 2004). It is likely that an individual experiencing sexism or SH at work will confide in his or her special peers who may influence how that individual thinks about and responds to the situation. Researchers may wish to collect qualitative data about disclosures to special peers about experiences of SH at work and code the responses for sexist undertones.

\section{Conclusion}

Although many tested hypotheses in this thesis emerged as insignificant, and the emergent correlations were small, the findings did confirm that sexist attitudes in participants, partners, and the workplace are somewhat linked to how the participants interpret and respond to sexually harassing behaviors at work. Now that these relationships have been established, future research may wish to investigate how workplace cultures characterized by sexism and SH are established and maintained through sexist communication of both victims and perpetrators as well as how this communication is influenced by close others in both personal and professional 
spheres. In order to address and eliminate sexually harassing behaviors in the workplace, we must first investigate the nuances of underlying sexist attitudes in those who establish, maintain, and respond to cultures of sexism and the connections between these individuals.

The results of this study support previous research, suggesting that the pervasiveness of sexism in the workplace culture coincides with women's intolerance of SH and whether or not they identify workplace behaviors as harassment. Organizations should seek to establish a culture in which employees are trained to identify a range of sexually harassing behaviors and subsequently report. The results also help to illuminate the connected, but distinct, ways in which women's own benevolent and hostile sexism function to perpetuate stereotypes and unknowingly sanction harassing behaviors in the workplace. In order to combat this, women should both challenge gender stereotypes and actively support victims of SH in their workplace.

Furthermore, although there appears to be a link between perceived partner HS and participants' intolerance for $\mathrm{SH}$, the findings in the research question suggest that women and men make major life choices and develop attitudes similarly across facets of life like relationships and work such that women may wish to confront and reflect upon their own sexist attitudes and how it may impact these decisions. Finally, although relationships between perceived partners' sexism and intolerance for and reporting of SH did emerge as we had hoped to a small degree, it is still interesting to consider the possibility that partners who are more benevolently sexist may feel a greater responsibility to protect their female partner from harassment at work. Therefore, participants' partners may still communicate benevolently sexist ideals even in support of reporting incidents of sexual harassment at work. Although support of this action is positive, it is important for both women and their partners to identify if this support is motivated by problematic sexist attitudes. Future research may wish to investigate in greater 
depth how such protective paternalism influences interpretation of benevolently sexist communication from others in both personal and professional contexts. 


\section{References}

Acar, F. P., \& Sümer, H. C. (2018). Another test of gender differences in assignments to precarious leadership positions: Examining the moderating role of ambivalent sexism. Applied Psychology, 67(3), 498-522. https://doi.org/10.1111/apps.12142

Brands, R. A., \& Kilduff, M. (2014). Just like a woman? Effects of gender-biased perceptions of friendship network brokerage on attributions and performance. Organization Science, 25(5), 1530-1548. https://doi.org/10.1287/orsc.2013.0880

Brock, R. L., \& Lawrence, E. (2008). A longitudinal investigation of stress spillover in marriage: Does spousal support adequacy buffer the effects? Journal of Family Psychology, 22(1), 11-20. https://doi.org/10.1037/0893-3200.22.1.11

Carnes, A. M. (2017). Bringing work stress home: The impact of role conflict and role overload on spousal marital satisfaction. Journal of Occupational and Organizational Psychology, 90(2), 153-176. https://doi.org/10.1111/joop.12163

Cesario, B., Parks-Stamm, E., \& Turgut, M. (2018). Initial assessment of the psychometric properties of the Sexual Harassment Reporting Attitudes Scale. Cogent Psychology, 5(1). https://doi.org/10.1080/23311908.2018.1517629

Chawla, N., Wong, E. M., \& Gabriel, A. S. (2019). Expanding the discourse surrounding sexual harassment: The case for considering experienced and observed hostile sexism, benevolent sexism, and gendered incivility. Industrial and Organizational Psychology, 12(01), 79-83. https://doi.org/10.1017/iop.2019.13

Chen, Z., Fiske, S. T., \& Lee, T. L. (2009). Ambivalent sexism and power-related gender-role ideology in marriage. Sex Roles, 60(11-12), 765-778. https://doi.org/10.1007/s11199-009-9585- 
Cohen, E. L., Myrick, J. G., \& Hoffner, C. A. (2019, May). What makes them believe her? Affinity and parasocial attachment interact to predict the social influence of celebrities' sexual harassment allegations. the annual meeting of the International Communication Association, Washington, D.C.

Conkel-Ziebell, J. L., Gushue, G. V., \& Turner, S. L. (2019). Anticipation of racism and sexism: Factors related to setting career goals for urban youth of color. Journal of Counseling Psychology, 66(5), 588-599. https://doi.org/10.1037/cou0000357

Connor, R. A., \& Fiske, S. T. (2019). Not minding the gap: How hostile sexism encourages choice explanations for the gender income gap. Psychology of Women Quarterly, 43(1), 22-36. https://doi.org/10.1177/0361684318815468

DeSouza, E. R., Solberg, J., \& Elder, C. (2007). A cross-cultural perspective on judgments of woman-to-woman sexual harassment: Does sexual orientation matter? Sex Roles, 56(7-8), 457471. https://doi.org/10.1007/s11199-007-9184-6

Devine, P. G., Forscher, P. S., Cox, W. T. L., Kaatz, A., Sheridan, J., \& Carnes, M. (2017). A gender bias habit-breaking intervention led to increased hiring of female faculty in STEMM departments. Journal of Experimental Social Psychology, 73, 211-215.

https://doi.org/10.1016/j.jesp.2017.07.002

Durán, M., Moya, M., \& Megías, J. L. (2011). It's his right, it's her duty: Benevolent sexism and the justification of traditional sexual roles. Journal of Sex Research, 48(5), 470-478. https://doi.org/10.1080/00224499.2010.513088

Feather, N. T., \& Boeckmann, R. J. (2007). Beliefs about gender discrimination in the workplace in the context of affirmative action: Effects of gender and ambivalent attitudes in an Australian sample. Sex Roles, 57(1-2), 31-42. https://doi.org/10.1007/s11199-007-9226-0 
Finneman, T., \& Jenkins, J. (2018). Sexism on the set: Gendered expectations of TV broadcasters in a social media world. Journal of Broadcasting \& Electronic Media, 62(3), 479494. https://doi.org/10.1080/08838151.2018.1484292

Fiske, S. T., \& Glick, P. (1995). Ambivalence and stereotypes cause sexual harassment: A theory with implications for organizational change. Journal of Social Issues, 51(1), 97-115. https://doi.org/10.1111/j.1540-4560.1995.tb01311.x

Glick, P., Lameiras, M., \& Castro, Y. R. (2002). Education and Catholic religiosity as predictors of hostile and benevolent sexism toward women and men. Sex Roles, 47, 433-441.

Good, J. J., \& Sanchez, D. T. (2009). Communal stereotypes prime men's benevolent sexism: Implications for romance and family. Psychology of Men \& Masculinity, 10(1), 88-94. https://doi.org/10.1037/a0013427

Goodwin, R., Graham, J., \& Diekmann, K. A. (2020). Good intentions aren't good enough: Moral courage in opposing sexual harassment. Journal of Experimental Social Psychology, 86, 103894. https://doi.org/10.1016/j.jesp.2019.103894

Hammond, M. D., \& Overall, N. C. (2017). Sexism in intimate contexts: How romantic relationships explain the origin, functions, and consequences of sexist attitudes. In C. G. Sibley \& F. K. Barlow (Eds.), The Cambridge Handbook of the Psychology of Prejudice. Cambridge University Press. https://psycnet.apa.org/doi/10.1017/9781316161579.014

Hammond, Matthew D., \& Overall, N. C. (2013). When relationships do not live up to benevolent ideals: Women's benevolent sexism and sensitivity to relationship problems. European Journal of Social Psychology, 43(3), 212-223. https://doi.org/10.1002/ejsp.1939 Hammond, Matthew D., Overall, N. C., \& Cross, E. J. (2016). Internalizing sexism within close relationships: Perceptions of intimate partners' benevolent sexism promote women's 
endorsement of benevolent sexism. Journal of Personality and Social Psychology, 110(2), 214238. https://doi.org/10.1037/pspi0000043

Hammond, Matthew D., Sibley, C. G., \& Overall, N. C. (2014). The allure of sexism:

Psychological entitlement fosters women's endorsement of benevolent sexism over time. Social Psychological and Personality Science, 5(4), 422-429.

https://doi.org/10.1177/1948550613506124

Heilman, M. E. (1983). Sex bias in work settings: The Lack of Fit model. Research in Organizational Behavior, 5, 296-298.

Heilman, Madeline E., \& Caleo, S. (2018). Combatting gender discrimination: A lack of fit framework. Group Processes \& Intergroup Relations, 21(5), 725-744.

https://doi.org/10.1177/1368430218761587

Helms, H. M., Walls, J. K., Crouter, A. C., \& McHale, S. M. (2010). Provider role attitudes, marital satisfaction, role overload, and housework: A dyadic approach. Journal of Family Psychology, 24(5), 568-577. https://doi.org/10.1037/a0020637

Hideg, I., \& Shen, W. (2019). Why still so few? A theoretical model of the role of benevolent sexism and career support in the continued underrepresentation of women in leadership positions. Journal of Leadership \& Organizational Studies, 26(3), 287-303.

https://doi.org/10.1177/1548051819849006

Horne, S. G., \& Biss, W. J. (2009). Equality discrepancy between women in same-sex relationships: The mediating role of attachment in relationship satisfaction. Sex Roles, 60(9-10), 721-730. https://doi.org/10.1007/s11199-008-9571-7

Huffman, A. H., Matthews, R. A., \& Irving, L. H. (2017). Family fairness and cohesion in marital dyads: Mediating processes between work-family conflict and couple psychological 
distress. Journal of Occupational and Organizational Psychology, 90(1), 95-116. https://doi.org/10.1111/joop.12165

Hughes, C. C., Schilt, K., Gorman, B. K., \& Bratter, J. L. (2017). Framing the faculty gender gap: A view from STEM doctoral students. Gender, Work \& Organization, 24(4), 398-416. https://doi.org/10.1111/gwao.12174

Jacobson, R. K., \& Eaton, A. A. (2018). How Organizational Policies Influence Bystander Likelihood of Reporting Moderate and Severe Sexual Harassment at Work. Employee Responsibilities and Rights Journal, 30(1), 37-62. https://doi.org/10.1007/s10672-017-9309-1 Jenkins, A. S., \& Mazer, J. P. (2018). \#NotOkay: Stories of sexual assault in the midst of the 2016 U.S. presidential election. Qualitative Research Reports in Communication, 19(1), 9-17. https://doi.org/10.1080/17459435.2017.1404487

Kapoor, U., Pfost, K. S., House, A. E., \& Pierson, E. (2010). Relation of success and nontraditional career choice to selection for dating and friendship. Psychological Reports, 107(1), 177-184. https://doi.org/10.2466/07.17.PR0.107.4.177-184

Karami, A., Swan, S. C., White, C. N., \& Ford, K. (2019). Hidden in plain sight for too long: Using text mining techniques to shine a light on workplace sexism and sexual harassment. Psychology of Violence. https://doi.org/10.1037/vio0000239

Kassing, J. W. (2000a). Investigating the relationship between superior-subordinate relationship quality and employee dissent. Communication Research Reports, 17(1), 58-69. https://doi.org/10.1080/08824090009388751

Kassing, J. W. (2000b). Exploring the relationship between workplace freedom of speech, organizational identification, and employee dissent. Communication Research Reports, 17(4), 387-396. https://doi.org/10.1080/08824090009388787 
Keyton, J., Ferguson, P., \& Rhodes, S. C. (2001). Cultural indicators of sexual harassment.

Southern Communication Journal, 67(1), 33-50. https://doi.org/10.1080/10417940109373217

Keyton, J., \& Menzie, K. (2007). Sexually harassing messages: Decoding workplace

conversation. Communication Studies, 58(1), 87-103.

https://doi.org/10.1080/10510970601168756

Keyton, J., \& Rhodes, S. C. (1999). Organizational sexual harassment: Translating research into application. Journal of Applied Communication Research, 27(2), 158-173.

https://doi.org/10.1080/00909889909365532

Keyton, J., \& Rhodes, S. C. (1993). Flirting and sexual harassment in the workplace: An exploratory study. 46.

Kim, Y.-I., \& Dew, J. (n.d.). Marital Investments and Community Involvement. Sociological Perspectives, 17.

Kram, K. E., \& Isabella, L. A. (1985). Mentoring alternatives: The role of peer relationships in career development. Academy of Management Journal, 28(1), 24.

Lease, S. H., Shuman, W. A., \& Gage, A. N. (2020). Female and male coworkers: Masculinity, sexism, and interpersonal competence at work. Psychology of Men \& Masculinities, 21(1), 139147. https://doi.org/10.1037/men0000218

Lee, T. L., Fiske, S. T., Glick, P., \& Chen, Z. (2010). Ambivalent sexism in close relationships: (Hostile) power and (benevolent) romance shape relationship ideals. Sex Roles, 62(7-8), 583601. https://doi.org/10.1007/s11199-010-9770-X

Lenton, A. P., \& Webber, L. (2006). Cross-sex friendships: Who has more? Sex Roles, 54(1112), 809-820. https://doi.org/10.1007/s11199-006-9048-5 
Manuel, S. K., Howansky, K., Chaney, K. E., \& Sanchez, D. T. (2017). No rest for the stigmatized: A model of organizational health and workplace sexism (OHWS). Sex Roles, 77(910), 697-708. https://doi.org/10.1007/s11199-017-0755-X

Mazerolle, S. M., Borland, J. F., \& Burton, L. J. (2012). The professional socialization of collegiate female athletic trainers: Navigating experiences of gender bias. Journal of Athletic Training, 47(6), 694-703. https://doi.org/10.4085/1062-6050-47.6.04

Melgoza, A. R., \& Cox, J. W. (2009). Subtle sexism: Re-informing intergroup bias and regulating emotion in an Australian police organization. Journal of Management \& Organization, 15(5), 652-666.

Moya, M., Glick, P., Expósito, F., de Lemus, S., \& Hart, J. (2007). It’s for your own good: Benevolent sexism and women's reactions to protectively justified restrictions. Personality and Social Psychology Bulletin, 33(10), 1421-1434. https://doi.org/10.1177/0146167207304790 Myers, S. A., \& Johnson, A. D. (2004). Perceived solidarity, self-disclosure, and trust in organizational peer relationships. Communication Research Reports, 21(1), 75-83. https://doi.org/10.1080/08824090409359969

Pacilli, M. G., Spaccatini, F., Giovannelli, I., Centrone, D., \& Roccato, M. (2019). System justification moderates the relation between hostile (but not benevolent) sexism in the workplace and state anxiety: An experimental study. The Journal of Social Psychology, 159(4), 474-481. https://doi.org/10.1080/00224545.2018.1503993

Pepli, A., Godlewska-Werner, D., Po, P., \& Lewandowska-Walter, A. (n.d.). Work involvement and the quality of two-career marital relationships - the mediating role of stress and role conflicts. 11. 
Quesenberry, J. L., \& Trauth, E. M. (2012). The (dis)placement of women in the IT workforce: An investigation of individual career values and organisational interventions: The (dis)placement of women in the IT workforce. Information Systems Journal, 22(6), 457-473.

https://doi.org/10.1111/j.1365-2575.2012.00416.x

Ruiz, A. G. (2019). White knighting: How help reinforces gender differences between men and women. Sex Roles, 81(9-10), 529-547. https://doi.org/10.1007/s11199-019-01018-y

Rumrill, J., Stehel, V., Durana, P., \& Kolencik, J. (2018). Does sexual objectification entail instutional power imbalances in organizations? Contemporary Readings in Law and Social Justice, 10(2), 100. https://doi.org/10.22381/CRLSJ102201810

Settles, I. H., \& O’Connor, R. C. (2014). Incivility at academic conferences: Gender differences and the mediating role of climate. Sex Roles, 71(1-2), 71-82. https://doi.org/10.1007/s11199014-0355-y

Sheppard, L. D., \& Aquino, K. (2017). Sisters at arms: A theory of female same-sex conflict and its problematization in organizations. Journal of Management, 43(3), 691-715. https://doi.org/10.1177/0149206314539348

Singletary Walker, S., Ruggs, E. N., Taylor, R. M., \& Frazier, M. L. (2019). Reporting sexual harassment: The role of psychological safety climate. Industrial and Organizational Psychology, 12(01), 106-109. https://doi.org/10.1017/iop.2019.19

Sollitto, M., \& Myers, S. A. (2015). Peer coworker relationships: Influences on the expression of lateral dissent. Communication Reports, 28(1), 36-47.

https://doi.org/10.1080/08934215.2014.925569 
Spillan, J. E., \& Mino, M. (2001). Special peers' perceived use of communication openness and functional communication skills in specific organizational contexts. Communication Research Reports, 18(1), 53-66. https://doi.org/10.1080/08824090109384782

Sümer, H. C. (2006). Women in management: Still waiting to be full members of the club. Sex Roles, 55(1-2), 63-72. https://doi.org/10.1007/s11199-006-9059-2

Turner, J. C., \& Tajfel, H. (1986). The social identity theory of intergroup behavior. Psychology of Intergroup Relations, 5, 7-24.

Umukoro, S., \& Oboh, G. A. (2017). DUAL-CAREER COUPLES: IMPLICATIONS FOR WORK-LIFE BALANCE. 3(6), 17.

Viki, G. T., Abrams, D., \& Hutchison, P. (2003). The "true" romantic: Benevolent sexism and paternalistic chivalry. Sex Roles, 49, 5.

Watkins, M. B., Kaplan, S., Brief, A. P., Shull, A., Dietz, J., Mansfield, M.-T., \& Cohen, R. (2006). Does it pay to be a sexist? The relationship between modern sexism and career outcomes. Journal of Vocational Behavior, 69(3), 524-537.

https://doi.org/10.1016/j.jvb.2006.07.004

Xie, J., Shi, Y., \& Ma, H. (2017). Relationship between similarity in work-family centrality and marital satisfaction among dual-earner couples. Personality and Individual Differences, 113, 103-108. https://doi.org/10.1016/j.paid.2017.03.021

Yucel, D. (2017). Work-family Balance and Marital Satisfaction: The Mediating Effects of Mental and Physical Health. Society and Mental Health, 7(3), 175-195.

https://doi.org/10.1177/2156869317713069 
Zakrisson, I., Anderzén, M., Lenell, F., \& Sandelin, H. (2012). Ambivalent sexism: A tool for understanding and improving gender relations in organizations. Scandinavian Journal of Psychology, 53(1), 64-70. https://doi.org/10.1111/j.1467-9450.2011.00900.x 
Table 1.1

Demographic Characteristics of Participants $(\mathrm{N}=145)$

\begin{tabular}{|c|c|c|c|}
\hline Characteristic & $n$ & & $\%$ \\
\hline \multicolumn{4}{|l|}{ Annual income (\$) } \\
\hline Less than $\$ 10,000$ & 18 & & 12.4 \\
\hline$\$ 10,000-\$ 19,999$ & 7 & & 4.8 \\
\hline$\$ 20,000-\$ 29,999$ & 5 & & 3.4 \\
\hline$\$ 30,000-\$ 39,999$ & 7 & & 4.8 \\
\hline$\$ 40,000-\$ 49,999$ & 3 & & 2.1 \\
\hline$\$ 50,000-\$ 59,999$ & 11 & & 7.6 \\
\hline$\$ 60,000-\$ 69,999$ & 13 & & 9.0 \\
\hline$\$ 70,000-\$ 79,999$ & 9 & & 6.2 \\
\hline$\$ 80,000-\$ 89,999$ & 10 & & 6.9 \\
\hline$\$ 90,000-\$ 99,999$ & 8 & & 5.5 \\
\hline$\$ 100,000-\$ 149,999$ & 28 & & 19.3 \\
\hline More than $\$ 150,000$ & 25 & & 17.2 \\
\hline \multicolumn{4}{|l|}{ Highest education level completed } \\
\hline High School & 43 & & 29.7 \\
\hline Vocational Training & 1 & & 0.7 \\
\hline Associate's Degree & 13 & & 9.0 \\
\hline Bachelor's Degree & 58 & & 40.0 \\
\hline Masters & 19 & & 13.1 \\
\hline Doctorate/Ph.D. & 3 & & 2.1 \\
\hline Other & 8 & & 5.5 \\
\hline \multicolumn{4}{|l|}{ Relationship Status } \\
\hline Married & 52 & & 35.9 \\
\hline In a domestic partnership or civil union & 3 & & 2.1 \\
\hline Cohabiting with a significant other & 27 & & 18.6 \\
\hline Committed relationship, living separately & 63 & & 43.3 \\
\hline \multicolumn{4}{|l|}{ Relationship Satisfaction (Range 1-7) } \\
\hline & $M=6.32$ & $S D=0.98$ & \\
\hline \multicolumn{4}{|l|}{ Organization Size } \\
\hline Less than 100 employees & 79 & & 54.5 \\
\hline 101-999 employees & 25 & & 17.2 \\
\hline Over 1,000 employees & 34 & & 23.4 \\
\hline \multicolumn{4}{|l|}{ Telecommute } \\
\hline Yes & 51 & & 35.2 \\
\hline No & 94 & & 64.8 \\
\hline \multicolumn{4}{|l|}{ Position } \\
\hline Top Management & 12 & & 8.3 \\
\hline Management & 58 & & 40.0 \\
\hline Other & 75 & & 51.7 \\
\hline \multicolumn{4}{|l|}{ Organization Type } \\
\hline Advertising & 4 & & 2.8 \\
\hline Aviation & 1 & & 0.7 \\
\hline Banking/Financial Services & 8 & & 5.5 \\
\hline Computer/Information Technology & 5 & & 3.4 \\
\hline
\end{tabular}




$\begin{array}{lll}\text { Construction } & 4 & 2.8 \\ \text { Consulting } & 1 & 0.7 \\ \text { Education } & 14 & 9.7 \\ \text { Food Service } & 25 & 17.2 \\ \text { Government/Public Service } & 9 & 6.2 \\ \text { Healthcare } & 24 & 16.6 \\ \text { Insurance } & 2 & 1.4 \\ \text { Journalism/Media } & 1 & 0.7 \\ \text { Law Enforcement } & 1 & 0.7 \\ \text { Manufacturing } & 4 & 2.8 \\ \text { Nonprofit } & 3 & 2.1 \\ \text { Recreation } & 4 & 2.8 \\ \text { Retail Sales } & 11 & 7.6 \\ \text { Sales } & 5 & 3.4 \\ \text { Service Industry } & 6 & 4.1 \\ \text { Transport } & 1 & 0.7 \\ \text { Other } & 12 & 8.3\end{array}$

Note. Totals of percentages are not 100 for every characteristic because of rounding.

Table 1.2

Demographic Characteristics of Participants $(\mathrm{N}=145)$

\begin{tabular}{lcc}
\hline \multicolumn{1}{c}{ Characteristic } & $M$ & $S D$ \\
\hline Relationship Duration (years) & 8.72 & 9.66 \\
Work Experience (years) & 12.20 & 11.16 \\
Current Employment (years) & 5.56 & 7.51 \\
\hline
\end{tabular}


Table 2

Reporting Sexual Harassment Behaviors ( $\mathrm{N}=145)$

\begin{tabular}{|c|c|c|c|}
\hline Behavior & $n$ & & $\%$ \\
\hline \multicolumn{4}{|c|}{ An unwanted sexual comment } \\
\hline \multicolumn{4}{|c|}{ Is this sexual harassment? } \\
\hline Yes & 124 & & 85.5 \\
\hline No & 21 & & 14.5 \\
\hline \multicolumn{4}{|c|}{ Would you report if it happened to you? } \\
\hline Yes & 63 & & 43.4 \\
\hline No & 82 & & 56.6 \\
\hline \multicolumn{4}{|c|}{ Would you report if it happened to a coworker? } \\
\hline Yes & 68 & & 46.9 \\
\hline No & 77 & & 53.1 \\
\hline \multicolumn{4}{|c|}{ How unrealistic is this behavior? (Range 1-7) } \\
\hline & $M=2.33$ & $S D=1.71$ & \\
\hline \multicolumn{4}{|l|}{ Inappropriate touching } \\
\hline \multicolumn{4}{|c|}{ Is this sexual harassment? } \\
\hline Yes & 137 & & 94.5 \\
\hline No & 8 & & 5.5 \\
\hline \multicolumn{4}{|c|}{ Would you report if it happened to you? } \\
\hline Yes & 127 & & 87.6 \\
\hline No & 18 & & 12.4 \\
\hline \multicolumn{4}{|c|}{ Would you report if it happened to a coworker? } \\
\hline Yes & 117 & & 80.7 \\
\hline No & 28 & & 19.3 \\
\hline \multicolumn{4}{|c|}{ How unrealistic is this behavior? (Range 1-7) } \\
\hline & $M=3.63$ & $S D=1.89$ & \\
\hline \multicolumn{4}{|c|}{ Inappropriate exposure of genitals or breasts } \\
\hline \multicolumn{4}{|c|}{ Is this sexual harassment? } \\
\hline Yes & 136 & & 93.8 \\
\hline No & 9 & & 6.2 \\
\hline \multicolumn{4}{|c|}{ Would you report if it happened to you? } \\
\hline Yes & 128 & & 88.3 \\
\hline No & 17 & & 11.7 \\
\hline \multicolumn{4}{|c|}{ Would you report if it happened to a coworker? } \\
\hline Yes & 130 & & 89.7 \\
\hline No & 15 & & 10.3 \\
\hline \multicolumn{4}{|c|}{ How unrealistic is this behavior? (Range 1-7) } \\
\hline & $M=4.69$ & $S D=1.80$ & \\
\hline \multicolumn{4}{|c|}{ An unwanted solicitation for sex } \\
\hline \multicolumn{4}{|c|}{ Is this sexual harassment? } \\
\hline Yes & 136 & & 93.8 \\
\hline No & 9 & & 6.2 \\
\hline \multicolumn{4}{|c|}{ Would you report if it happened to you? } \\
\hline Yes & 125 & & 86.2 \\
\hline No & 20 & & 13.8 \\
\hline
\end{tabular}

Would you report if it happened to a coworker? 
Yes

No

How unrealistic is this behavior? (Range 1-7)
120

25
82.8

17.2

$$
M=3.99 \quad S D=2.00
$$

Note. Totals of percentages are not 100 for every characteristic because of rounding. 
Table 3

Correlations Between Hypothesized Variables When Controlling for Relationship Duration, Relationship Satisfaction, Income, Education, Organization Size, and Number of Special Peers at Work

\begin{tabular}{|c|c|c|c|c|c|c|c|c|}
\hline Variable & 1 & 2 & 3 & 4 & 5 & 6 & 7 & 8 \\
\hline 1. Reporting & & & & & & & & \\
\hline SH & - & $.37^{\wedge}$ & $-.18 *$ & -.11 & -.05 & -.17 & -.11 & -.13 \\
\hline $\begin{array}{l}\text { 2. Intolerance } \\
\text { for } \mathrm{SH}\end{array}$ & $.37^{\wedge}$ & - & -.13 & $-.20 *$ & $-.26 *$ & $-.29 *$ & $-.23 *$ & $-.40^{\wedge}$ \\
\hline 3. Partner BS & $-.18 *$ & -.13 & - & $.33^{\wedge}$ & $.43^{\wedge}$ & $.29 *$ & $.61^{\wedge}$ & $.28 *$ \\
\hline 4. Partner HS & $-.20 *$ & .11 & $.33^{\wedge}$ & - & .16 & $.46^{\wedge}$ & $.24 *$ & $.65^{\wedge}$ \\
\hline $\begin{array}{l}\text { 5. Workplace } \\
\text { BS }\end{array}$ & -.05 & $.26^{*}$ & $.43^{\wedge}$ & .16 & - & $.52^{\wedge}$ & $.65^{\wedge}$ & $.36^{\wedge}$ \\
\hline $\begin{array}{l}\text { 6. Workplace } \\
\text { HS }\end{array}$ & -.17 & $.29 *$ & $.29 *$ & $.46^{\wedge}$ & $.52^{\wedge}$ & - & $.43^{\wedge}$ & $.62^{\wedge}$ \\
\hline $\begin{array}{l}\text { 7. Participant } \\
\text { BS }\end{array}$ & -.11 & $-.23 *$ & $.61^{\wedge}$ & $.24 *$ & $.65^{\wedge}$ & $.43^{\wedge}$ & - & $.45^{\wedge}$ \\
\hline $\begin{array}{l}\text { 8. Participant } \\
\text { HS }\end{array}$ & -.13 & $-.40^{\wedge}$ & $.28 *$ & $.65^{\wedge}$ & $.36^{\wedge}$ & $.62^{\wedge}$ & $.45^{\wedge}$ & - \\
\hline
\end{tabular}

Note: ${ }^{*} p<.05 ; \wedge p<.01 . S H=$ sexual harassment $; B S=$ benevolent sexism; $H S=$ hostile sexism 
Table 4

Correlation Matrix

\begin{tabular}{|c|c|c|c|c|c|c|c|c|c|c|c|c|c|c|c|}
\hline 1. Age & - & $.42^{\wedge}$ & $.34^{\wedge}$ & $.85^{\wedge}$ & -.06 & $.36^{\wedge}$ & .09 & -.11 & .02 & -.09 & -.08 & -.09 & -.09 & .08 & $.17 *$ \\
\hline 2. Income & $.42^{\wedge}$ & - & $.22^{\wedge}$ & $.41^{\wedge}$ & -.01 & $.27^{\wedge}$ & .02 & -.04 & -.02 & -.11 & -.13 & -.05 & -.08 & -.03 & .02 \\
\hline 3. Education & $.34^{\wedge}$ & $.22^{\wedge}$ & - & $.23^{\wedge}$ & -.09 & $.33^{\wedge}$ & .04 & -.15 & $-.18 *$ & $-.23^{\wedge}$ & $-.29^{\wedge}$ & $-.22^{\wedge}$ & $-.26^{\wedge}$ & .14 & .03 \\
\hline $\begin{array}{l}\text { 4. Relationship } \\
\text { Duration }\end{array}$ & $.85^{\wedge}$ & $.41^{\wedge}$ & $.23^{\wedge}$ & - & -.01 & $.26^{\wedge}$ & .07 & -.01 & .12 & -.04 & -.05 & -.04 & .05 & .10 & $.17 *$ \\
\hline $\begin{array}{l}\text { 5. Relationship } \\
\text { Satisfaction }\end{array}$ & -.05 & -.01 & -.09 & -.01 & - & -.10 & -.03 & .10 & -.08 & .13 & .03 & .10 & .09 & .15 & .12 \\
\hline 7. Special Peers & .09 & .02 & .04 & .04 & -.03 & -.05 & - & -.07 & $-.18 *$ & -.05 & -.09 & -.10 & -.12 & .01 & .07 \\
\hline 8. Partner BS & -.11 & -.04 & -.15 & -.01 & .10 & -.04 & -.07 & - & $.36^{\wedge}$ & $.45^{\wedge}$ & $.31^{\wedge}$ & $.61^{\wedge}$ & $.32^{\wedge}$ & $-.18 *$ & -.12 \\
\hline 9. Partner HS & -.02 & -.02 & $-.18^{\wedge}$ & .12 & -.08 & .01 & $-.18 *$ & $.36^{\wedge}$ & - & $.18^{*}$ & $.46^{\wedge}$ & $.28^{\wedge}$ & $.65^{\wedge}$ & -.13 & $-.18 *$ \\
\hline
\end{tabular}




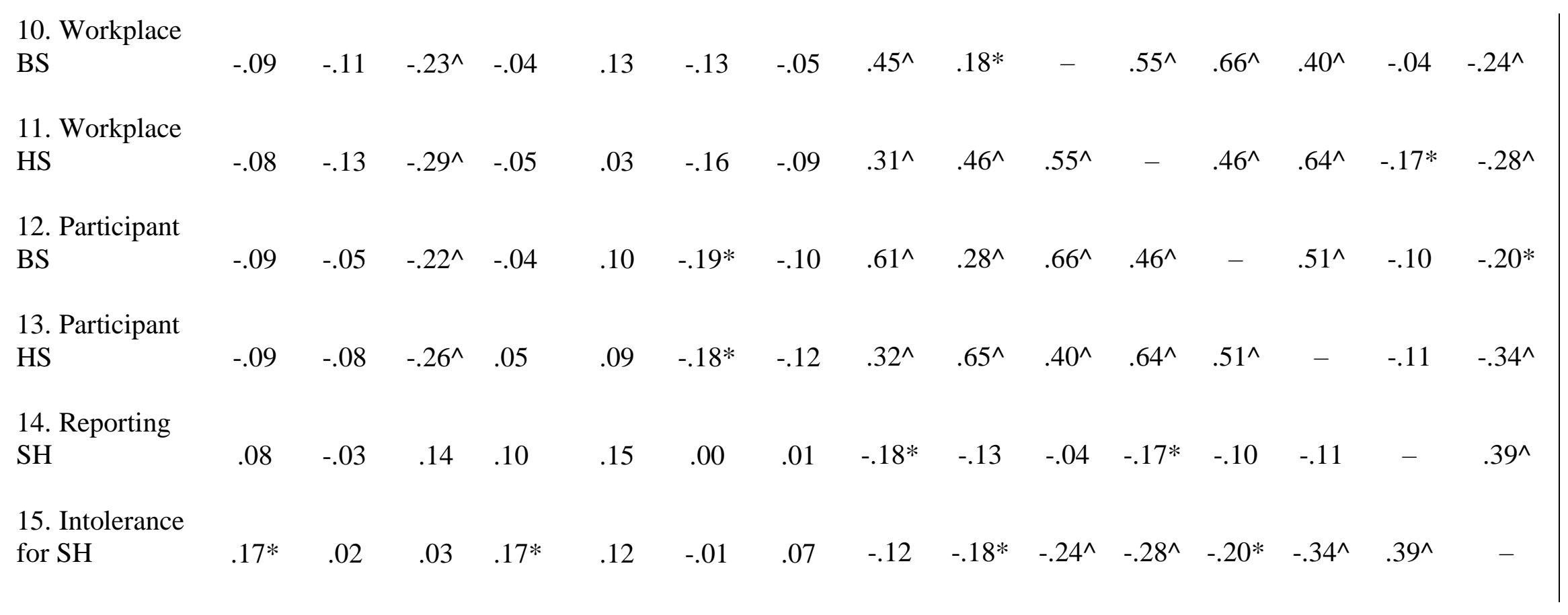




\section{Appendix}

Dear Participant,

This letter is a request for you to take part in a research project exploring how working women's close interpersonal relationships affect their tolerance for sexual harassment and likelihood of reporting sexual harassment at work. This study is being conducted by Investigator Rachael Purtell, under the supervision of Principal Investigator Dr. Christine Rittenour, in the Department of Communication Studies at West Virginia University. Your participation in this project is greatly appreciated and it will take approximately 30 minutes of your time to complete this survey. Your involvement in this project will be anonymous. You must be a woman 18 years of age or older to participate, employed full-time, and either married or in a monogamous heterosexual relationship lasting longer than three years. You will not be asked to provide any information that should lead back to your identity as a participant. Your participation is completely voluntary. You may skip any question that you do not wish to answer, and you may discontinue at any time. West Virginia University's Institutional Review Board acknowledgement of this project is on file. If you or the individual who recruited you to participate in this study is receiving extra credit for this research in a Communication Studies class, you will be provided a link at the end of this survey that will ask you to provide information about yourself or the student and the class in which you wish to receive extra credit. The information that you provide for extra credit will not be linked to your survey responses. We hope that you will participate in this research project, as it could be beneficial in understanding how sexism and sexual harassment are communicated in the workplace. Thank you very much for your time. Should you have any questions about this letter or the research project, please feel free to contact Rachael Purtell at (304) 293-3905 or by e-mail at rep0027@mix.wvu.edu. Thank you for your time and help with this project! Rachael Purtell 
WVU Communication Studies M.A. Student

rep0027@mix.wvu.edu

I agree to participate in this study.

Please answer the following questions about yourself.

What is your age (in whole years)?

$18 \ldots 80+$

Which racial/ethnic background do you most closely identify with (check one)?

Asian/Asian American

Black/African American

Hispanic

Native American

White/Caucasian

Middle Eastern

Other (please specify): 
What is your household income?

Less than $\$ 10,000$
$\$ 10,000-\$ 19,999$
$\$ 20,000-\$ 29,999$
$\$ 30,000-\$ 39,999$
$\$ 40,000-\$ 49,999$
$\$ 50,000-\$ 59,999$
$\$ 60,000-\$ 69,999$
$\$ 70,000-\$ 79,999$
$\$ 80,000-\$ 89,999$
$\$ 90,000-\$ 99,999$
$\$ 100,000-\$ 149,999$
More than $\$ 150,000$ 
What is your highest level of education?
No formal education
High School
Vocational Training
Associate's Degree
Bachelor's Degree
Masters
Doctorate/Ph.D.
Other (please specify):

What is your current romantic relationship status?

Married

Committed relationship, living separately

Cohabiting with a significant other

In a domestic partnership or civil union

Widowed

Divorced

Separated

Single, never married 
How many total years have you been in this (current) romantic relationship?

Please rate how satisfied you are with your current romantic relationship.

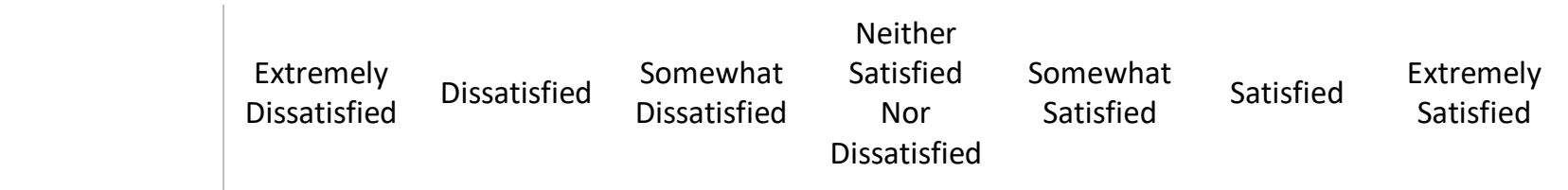

How

satisfied are

you with

your current

relationship?

Approximately how large is your organization?

Less than 100 employees

101-999 employees

Over 1,000 employees 
Do you telecommute?

Yes

No

How many total years of work experience do you have including your current and any past jobs?

How long have you been employed in your current job position? (in years)

What is your job title? 
Which term best describes your position?

Top Management

Management

Other (Please Specify): 
Which best describes your organization?

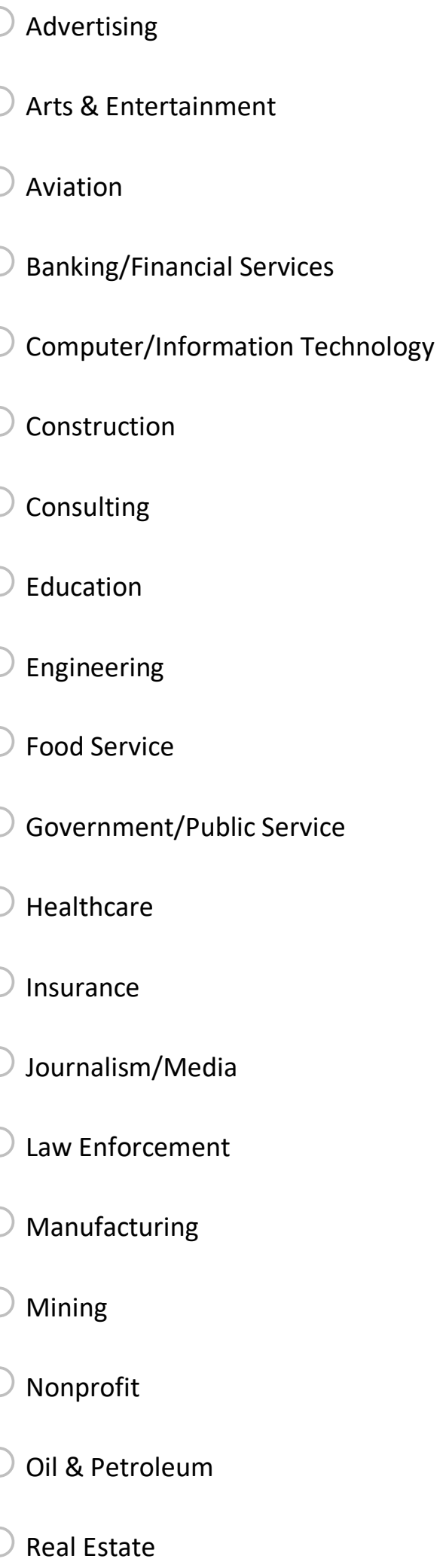




\author{
Recreation \\ Retail Sales \\ Sales \\ Service Industry \\ Telecommunications \\ Transport \\ Other, please specify
}

At work, we have information peers, collegial peers, and special peers. Special peers in the workplace are those with whom you have a great degree of self-disclosure and self-expression. Please indicate the number of special peers that you have in your workplace. 
Below are a series of statements concerning men and women and their relationships in contemporary society. Please indicate the degree to which you believe your romantic partner would either agree or disagree with each of the statements below: 


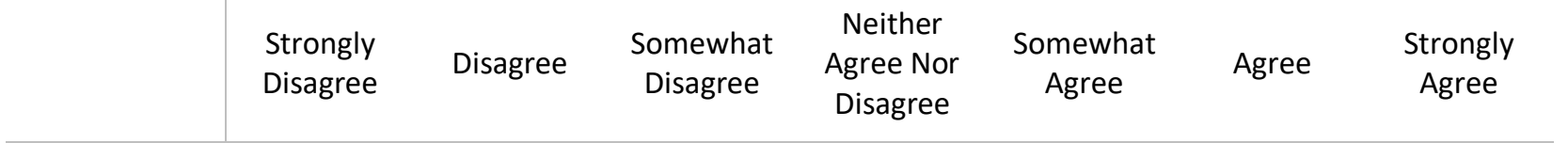

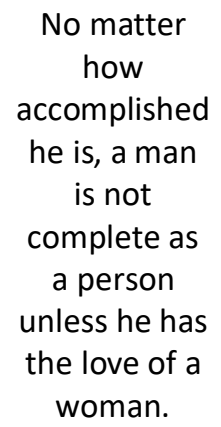

In a disaster, women ought not necessarily to be rescued before men.

Most women interpret innocent remarks or acts as being sexist.

Women are too easily offended. 


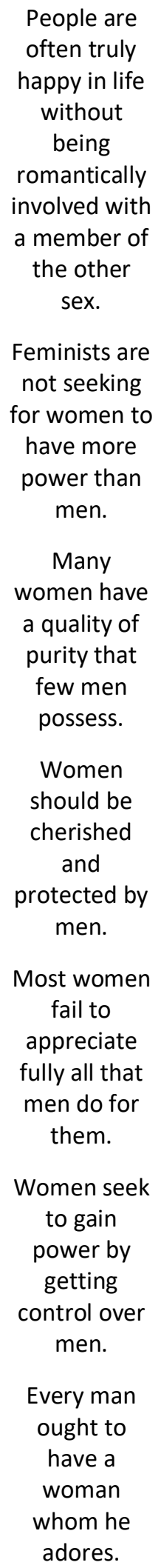

Most women fail to appreciate fully all that men do for them.

Women seek to gain power by getting control over men.

Every man ought to have a woman whom he adores. 


\author{
Men are \\ incomplete \\ without \\ women. \\ Women \\ exaggerate \\ problems \\ they have at \\ work. \\ Once a \\ woman gets \\ a man to \\ commit to \\ her, she \\ usually tries \\ to put him on \\ a tight lease.
}

When women lose to men in a

fair competition, they typically complain about being discriminated against.

A good woman should be set on a pedestal by her man.

There are actually very few women who get a kick out of teasing men by seeming sexually available and then refusing male advances. 


\author{
Women, \\ compared to \\ men, tend to \\ have a \\ superior \\ moral \\ sensibility. \\ Men should \\ be willing to \\ sacrifice their \\ own well- \\ being in \\ order to \\ provide \\ financially for \\ the women \\ in their lives. \\ Feminists are \\ making \\ entirely \\ reasonable \\ demands of \\ men. \\ Women, as \\ compared to \\ men, tend to \\ have a more \\ refined sense \\ of culture \\ and good \\ taste.
}


Below are a series of statements concerning men and women and their relationships in contemporary society. Please indicate the degree to which you believe the leaders in your workplace would either agree or disagree with each of the statements below: 


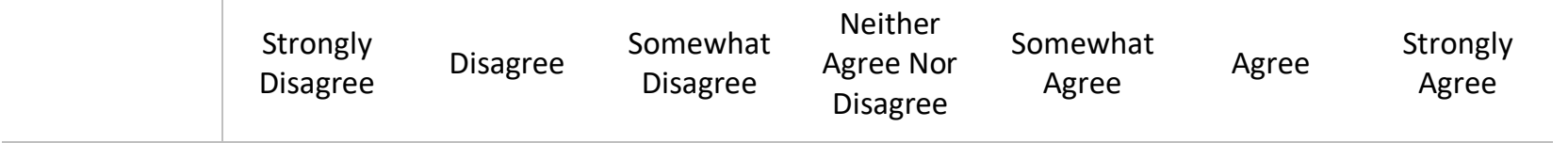

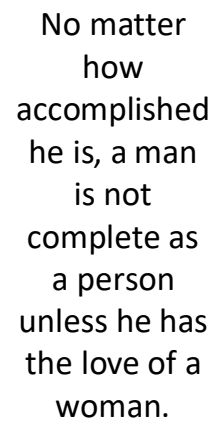

In a disaster, women ought not necessarily to be rescued before men.

Most women interpret innocent remarks or acts as being sexist.

Women are too easily offended. 


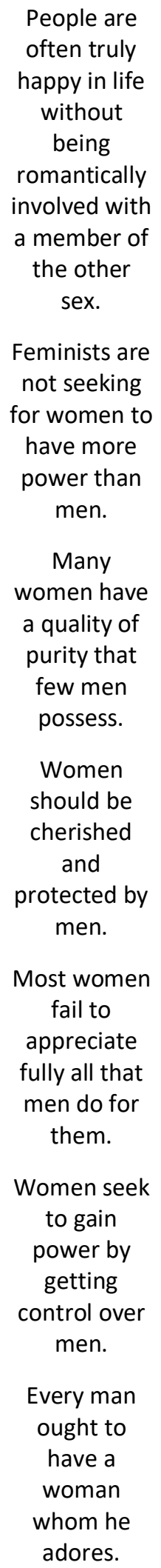

Most women fail to appreciate fully all that men do for them.

Women seek to gain power by getting control over men.

Every man ought to have a woman whom he adores. 


\footnotetext{
Men are

incomplete

without

women.

Women

exaggerate problems

they have at work.

Once a woman gets a man to commit to her, she usually tries to put him on a tight lease.

When women lose to men in a

fair competition, they typically complain about being discriminated against.

A good woman should be set on a pedestal by her man.

There are actually very few women who get a kick out of teasing men by seeming sexually available and then refusing male advances.
} 


\author{
Women, \\ compared to \\ men, tend to \\ have a \\ superior \\ moral \\ sensibility. \\ Men should \\ be willing to \\ sacrifice their \\ own well- \\ being in \\ order to \\ provide \\ financially for \\ the women \\ in their lives. \\ Feminists are \\ making \\ entirely \\ reasonable \\ demands of \\ men. \\ Women, as \\ compared to \\ men, tend to \\ have a more \\ refined sense \\ of culture \\ and good \\ taste.
}


Below are a series of statements concerning men and women and their relationships in contemporary society. Please indicate the degree to which you either agree or disagree with each of the statements below: 


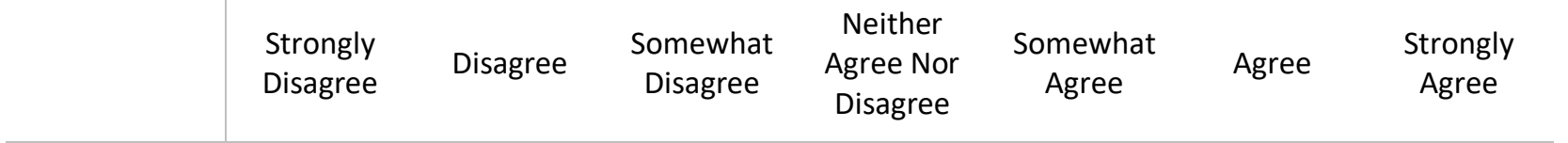

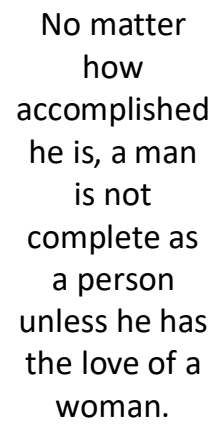

In a disaster, women ought not necessarily to be rescued before men.

Most women interpret innocent remarks or acts as being sexist.

Women are too easily offended. 


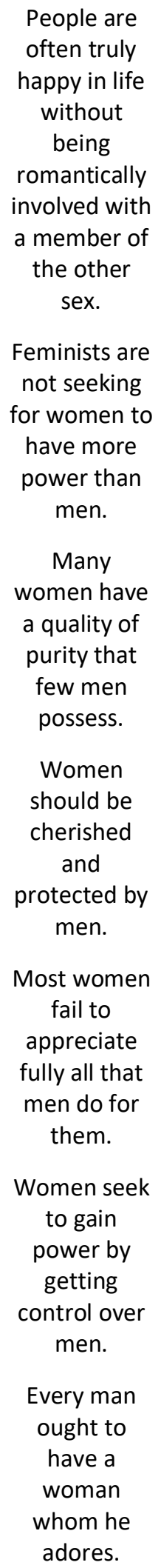

Most women fail to appreciate fully all that men do for them.

Women seek to gain power by getting control over men.

Every man ought to have a woman whom he adores. 


\author{
Men are \\ incomplete \\ without \\ women. \\ Women \\ exaggerate \\ problems \\ they have at \\ work. \\ Once a \\ woman gets \\ a man to \\ commit to \\ her, she \\ usually tries \\ to put him on \\ a tight lease.
}

When women lose to men in a

fair competition, they typically complain about being discriminated against.

A good woman should be set on a pedestal by her man.

There are actually very few women who get a kick out of teasing men by seeming sexually available and then refusing male advances. 


\author{
Women, \\ compared to \\ men, tend to \\ have a \\ superior \\ moral \\ sensibility. \\ Men should \\ be willing to \\ sacrifice their \\ own well- \\ being in \\ order to \\ provide \\ financially for \\ the women \\ in their lives. \\ Feminists are \\ making \\ entirely \\ reasonable \\ demands of \\ men. \\ Women, as \\ compared to \\ men, tend to \\ have a more \\ refined sense \\ of culture \\ and good \\ taste.
}


Please indicate to what degree you either agree or disagree with each of the statements below. 


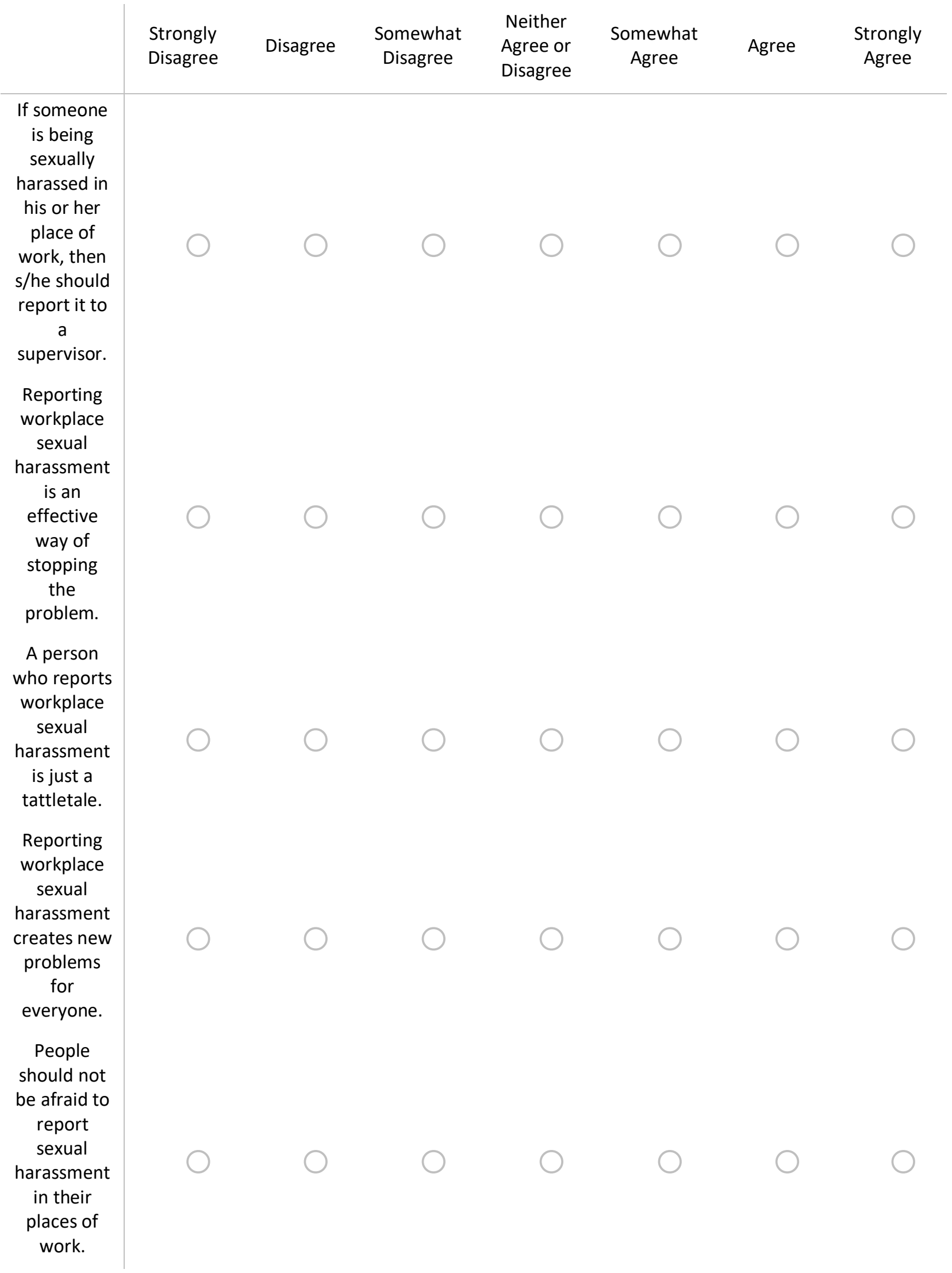




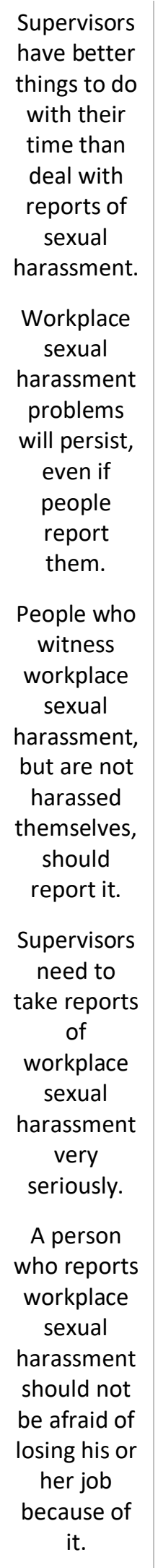




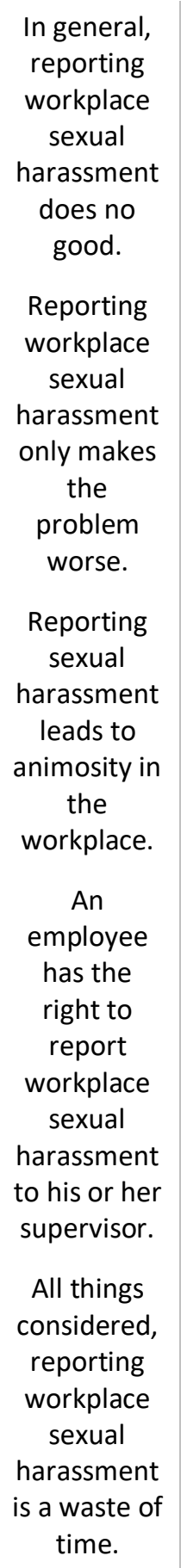




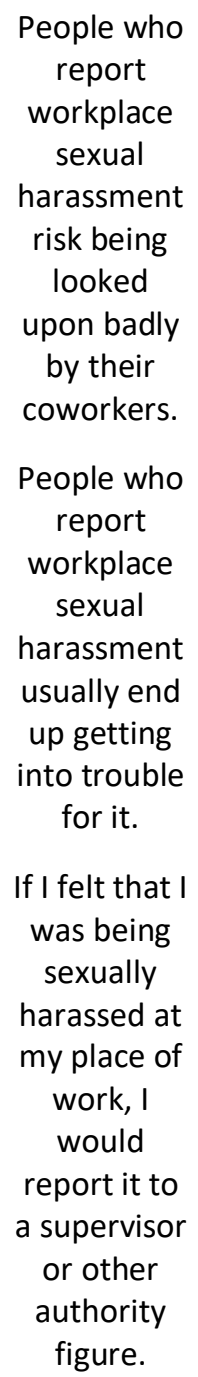

Please indicate whether or not you view each behavior listed below as sexual harassment and whether or not you would report the behavior described in the scenario below to a supervisor at your workplace if it happened to you or a coworker.

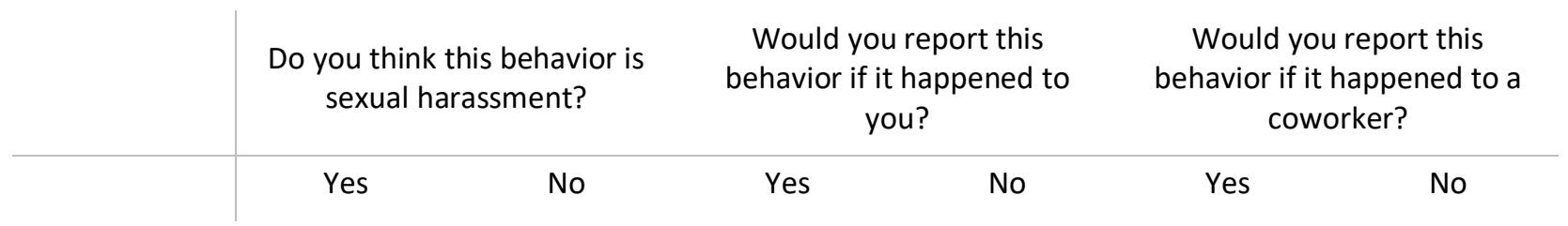




$\begin{gathered}\text { An unwanted } \\ \text { sexual } \\ \text { comment }\end{gathered}$
Inappropriate
touching
Inappropriate
exposure of
genitals or
breasts
An unwanted
solicitation
for sex

Please indicate how realistic it is for each of these behaviors to occur in the workplace.

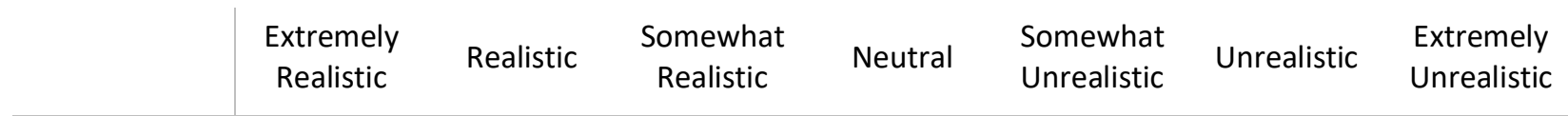

\footnotetext{
An unwanted sexual comment

Inappropriate touching

Inappropriate exposure of genitals or breasts

An unwanted solicitation for sex
} 
Have you or someone close to you been sexually harassed at work?

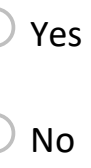

In the space below, please tell us anything else that you would like us to know about the things addressed in this survey.

Thank you so much for your time and help with this project. If you or an individual who recruited you to participate in this study are receiving extra credit in a Communication Studies course, please continue on and you will be brought to a new survey to fill in the required information to receive extra credit. If you are filling out someone else's information, be sure to obtain that information from the student who recruited you to participate in this study. 


\section{E-mail Recruitment Script}

The following message will be used as the script for recruitment of participants through WVU Students via E-mail.

"Hi everyone!

My name is Rachael Purtell and I am an M.A. student in the Department of Communication Studies here at WVU. I am currently conducting a research study on full-time employed women who are either married or in a self-defined committed monogamous relationship lasting three years of longer. I am contacting you today to possibly solicit your help! I am going to give you instructions about who can participate in this study and what they need to do if they choose to voluntarily participate.

To qualify to participate in this study you must be a female at least 18 years of age and currently employed full-time and involved in a heterosexual marriage or relationship lasting at least three years. Most of you will not meet the criteria, but if you know anyone that does qualify (for example, parents, friends, etc.) then you can reach out to them and still earn extra credit.

The survey can be found at:

\section{https://wvu.qualtrics.com/jfe/form/SV_8eUz8kK5YwTyO0Z}

After taking the survey, the participant will be able to enter your identifying information (for course credit) through a separate portal such that your identity is not linked to the participant's responses. Be sure that you tell the participant your full name, instructor name, course name so that you receive your proper credit. Of course, please thank them for their assistance.

If you do not want to participate or cannot find a married/committed woman to participate in this study, your grade and/or standing in the class will not be influenced. There are other research studies or alternative assignments you could completed instead. Please feel free to contact me, Rachael Purtell, at rep0027@mix.wvu.edu if you have any questions about this study.

Thank you for your time!

Sincerely, Rachael Purtell” 


\section{Facebook Recruitment Script}

Hello friends,

I am conducting a study on women (18 and older) who are employed full-time and are either married or in a monogamous heterosexual relationship lasting longer than three years. Under the supervision of my advisor and PI Dr. Christine E. Rittenour. This completed project will partially fulfill the requirements for my MA degree (Communication Studies - WVU). Participants' responses are completely anonymous. West Virginia University's IRB has acknowledgment of this study on file. If you fit the underlined criteria, I would appreciate you filling out my 30minute survey. Also, if you'd be kind enough to repost this on your social media, I would be very appreciative. Please contact me if you have any questions regarding this study. Here is the online survey link:

https://wvu.qualtrics.com/jfe/form/SV_8eUz8kK5YwTyO0Z

Thank you very much for your help!

Sincerely,

Rachael E. Purtell

M.A. Student

Department of Communication Studies

Co-Principal Investigator

rep0027@mix.wvu.edu 